\title{
Nanomaterials for Skin Delivery of Cosmeceuticals and Pharmaceuticals
}

\author{
Eliana B. Souto ${ }^{1,2, *(\mathbb{D})}$, Ana Rita Fernandes ${ }^{1}$ D , Carlos Martins-Gomes ${ }^{3,4}{ }^{\mathbb{D}}$, \\ Tiago E. Coutinho ${ }^{3,4} \mathbb{D}$, Alessandra Durazzo ${ }^{5} \mathbb{D}$, Massimo Lucarini ${ }^{5}$, Selma B. Souto ${ }^{6}$,
} Amélia M. Silva ${ }^{3,4}$ and Antonello Santini ${ }^{7, *(\mathbb{D}}$

1 Department of Pharmaceutical Technology, Faculty of Pharmacy, University of Coimbra, Pólo das Ciências da Saúde, Azinhaga de Santa Comba, 3000-548 Coimbra, Portugal; anaritavfernandes@gmail.com

2 CEB-Centre of Biological Engineering, University of Minho, Campus de Gualtar 4710-057 Braga, Portugal

3 Department of Biology and Environment, University of Trás-os-Montes e Alto Douro, UTAD, Quinta de Prados, P-5001-801 Vila Real, Portugal; camgomes@utad.pt (C.M.-G.); tecoutinho@utad.pt (T.E.C.); amsilva@utad.pt (A.M.S.)

4 Centre for Research and Technology of Agro-Environmental and Biological Sciences, CITAB, UTAD, Quinta de Prados, P-5001-801 Vila Real, Portugal

5 CREA-Research Centre for Food and Nutrition, Via Ardeatina 546, 00178 Rome, Italy; alessandra.durazzo@crea.gov.it (A.D.); massimo.lucarini@crea.gov.it (M.L.)

6 Department of Pharmacy, Università di Napoli Federico II, Via D. Montesano 49, 80131 Napoli, Italy; sbsouto.md@gmail.com

7 Department of Endocrinology of Hospital de São João, Alameda Prof. Hernâni Monteiro, 4200-319 Porto, Portugal

* Correspondence: ebsouto@ff.uc.pt (E.B.S.); asantini@unina.it (A.S.); Tel.: +351-239-488-400 (E.B.S.); +39-81-253-9317 (A.S.)

Received: 16 January 2020; Accepted: 24 February 2020; Published: 27 February 2020

Featured Application: The loading of pharmaceuticals and cosmeceuticals into nanomaterials is discussed as new formulations for potential treatment of age-related skin problems. Topical administration of active ingredients formulated as nanopharmaceuticals and nanonutraceuticals is discussed.

\begin{abstract}
Skin aging is described as dermatologic changes either naturally occurring over the course of years or as the result of the exposure to environmental factors (e.g., chemical products, pollution, infrared and ultraviolet radiations). The production of collagen and elastin, the main structural proteins responsible for skin strength and elasticity, is reduced during aging, while their role in skin rejuvenation can trigger a wrinkle reversing effect. Elasticity loss, wrinkles, dry skin, and thinning are some of the signs that can be associated with skin aging. To overcome skin aging, many strategies using natural and synthetic ingredients are being developed aiming to reduce the signs of aging and/or to treat age-related skin problems (e.g., spots, hyper- or hypopigmentation). Among the different approaches in tissue regeneration, the use of nanomaterials loaded with cosmeceuticals (e.g., phytochemicals, vitamins, hyaluronic acid, and growth factors) has become an interesting alternative. Based on their bioactivities and using different nanoformulations as efficient delivery systems, several cosmeceutical and pharmaceutical products are now available on the market aiming to mitigate the signs of aged skin. This manuscript discusses the state of the art of nanomaterials commonly used for topical administration of active ingredients formulated in nanopharmaceuticals and nanocosmeceuticals for skin anti-aging.
\end{abstract}

Keywords: skin aging; nanomaterials; nanocosmeceuticals; nanopharmaceuticals 


\section{Introduction}

Nanotechnology stands for the production and use of materials at the nanoscale, which show physicochemical properties different from their bulk counterparts. Due to special rearrangements of their inner structure, these new materials exhibit a larger surface area, thereby acting differently with biological systems [1]. The loading of active pharmaceutical ingredients (APIs) within nano-sized drug delivery systems is being currently exploited to promote product innovation by developing nanoproducts. Nanoproducts used for the delivery of APIs to the skin (e.g., nanopharmaceuticals, nanocosmeceuticals) have already proven their efficacy as several products are already available on the market for the treatment of skin injuries (e.g., atopic dermatitis [2], skin cancer [3], skin burns [4], wound healing [4,5]), and protection from ultraviolet (UV) radiations [6-10]. Some examples of daily contact with nanomaterials are given in Figure 1. A successful example is the formulation of sunscreens into nanoproducts. This approach was found to decrease the adverse side-effects of $U V$ inorganic filters (e.g., titanium dioxide $\left(\mathrm{TiO}_{2}\right)$, zinc oxide ( $\left.\mathrm{ZnO}\right)$ [11]) and of chemical filters (benzophenone-3 [7,12]), improving the safety to consumers [8-10]. Besides, it has also been demonstrated that the loading of sunscreen into solid nanoparticles can offer a synergistic effect, as nanoparticles can themselves have a sun-blocking effect [13].

In the past years, different types of nanoparticles have been proposed to load sunscreens, antioxidants and vitamins for skin care formulations. The first cosmetic products manufactured using nanotechnology were the liposomes-containing moisturizing creams, launched 40 years ago [14]. Since then, several other types of biocompatible nanomaterials have been proposed, being nanoemulsions, solid lipid nanoparticles (SLN), nanostructured lipid carriers (NLC) of special interest due to their lipid composition. Besides, lipid nanoparticles also improve skin hydration because of the formation of a thin lipidic film onto the surface of the skin, retaining its moisture for longer time [15-17]).

Over the course of the 20th century, cosmetics raised their popularity as daily products with a substantial marketed increase [18,19]. Various cosmeceutical formulations for skin, body, and hair applications are being proposed for the treatment of a range of problems, such as hair damage and/or loss, wrinkles, hyperpigmentation, and photo-aging [20].

In the market of personal care products, cosmeceuticals and in particular, nanocosmeceuticals, show the greatest growth in the last decades [21]. The main advantages of nanocosmeceuticals include the controlled release of APIs site-specific targeting, occlusive properties with enhanced hydration, which contribute to increase skin permeation to the API [22]. Part of these advantages are also the reason why nanocosmeceuticals should be regulated and subject of clinical trials, a critical step to assure consumer's safety $[23,24]$. Nanoparticles can be highly reactive both in vitro and in vivo, resulting in an enhanced risk of toxicologic events [25-28].

Cosmeceuticals are used for a variety of applications, e.g., to improve skin texture by stimulating collagen growth, as anti-aging formulations as their antioxidants neutralize reactive oxygen species and protect the structure of keratin, which results in a healthier skin [29-31]. Marketed antiaging nanocosmeceuticals as hair care products (e.g., shampoos, conditioners, hair growth stimulants, coloring and styling products) may be composed of nanotubes, poly(lactic-co-glycolic acid (PLGA) nanospheres, fullerenes, gold nanoparticles, niosomes, microemulsions, nanoemulsions, liposomes, with the purpose of sealing the moisture around the cuticles and optimizing the contact time with the scalp and the follicles, by forming a protective film [32]. Nanocosmeceuticals have also been included in lipsticks, lip balms, lip glosses, and lip volumizers. The use of nanoparticles in lip-care products is aimed to increase the lip softness, to prevent the transepidermal water loss, and to keep the desired styling effect (e.g., a color) for a longer timeframe [33]. Lip volumizers containing nanocosmeceuticals are based on liposomes to increase the lip volume by filling the wrinkles in the lip contour, keeping the lips hydrated and well-outlined [22]. Nanocosmeceuticals have also been successful in the field of nail care. Nail polishers enhance the toughness, dry faster than conventional products, have more durability and resistance, and have a higher elasticity which facilitates the application [22]. The use of 
silver and metal oxide nanoparticles in these formulations provide them with antifungal properties, which is very useful for the treatment of toenails in case of fungal infections [34].

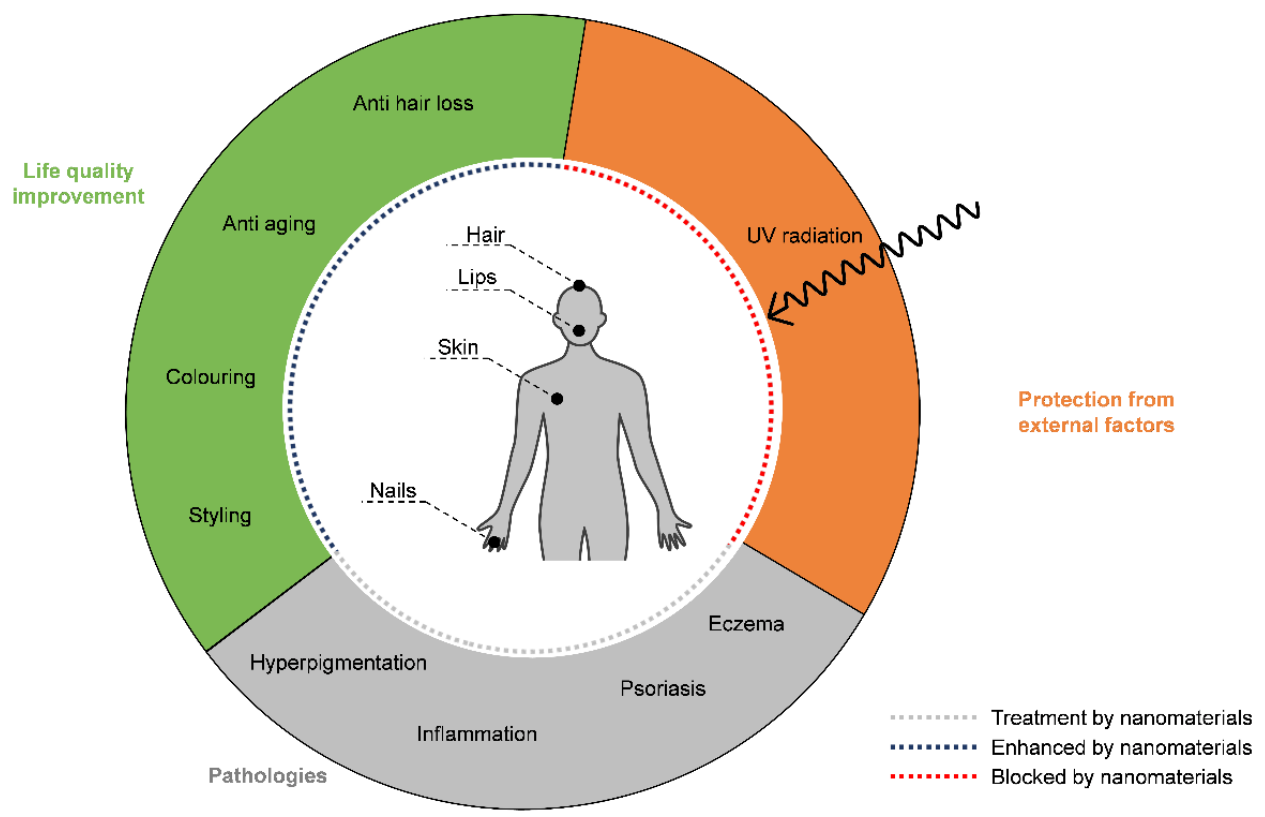

Figure 1. Applications of nanomaterials in the formulation of cosmetics and other products for topical application and their interaction with everyday human activities. Nanomaterials used in hair and skin care products promote quality of life by offering innovations in a range of applications and enhance sunscreen protection. Nanomaterials are also used as delivery system for a range of active pharmaceutical ingredients to treat several skin pathologies.

Due to their small size, nanoparticles may exhibit high reactivity and can induce the production of reactive oxygen species (ROS) that promote oxidative stress, DNA damage, proteins and membranes degradation, and inflammation $[26,35,36]$. The risk assessment of lipid peroxidation and oxidative stress induced by nanoparticles is a commonly recommended procedure $[25,28,35]$. The bioavailability of an active compound of nutraceutical or pharmaceutical interest [31,37-40], in the formulation of a cream, lotion, or cosmetic product, is defined by the concentration that reaches in a biological fluid, i.e., blood, which is available for a therapeutic effect. The bioavailability is more influenced by the properties of the dosage form, i.e., the design and formulation rather than of the physicochemical properties of the API. The physicochemical properties of the API influence the amount that will be absorbed [41]. The loading of APIs in nanoparticles is a common strategy to improve their bioavailability in particular for poorly water-soluble compounds. Besides, due to their enhanced surface area in contact with the skin, increased permeation of the skin to the compounds is also expected. Besides bioavailability, the size of the particles is instrumental in defining the toxicological profile, the shelf life, and the efficacy of the final nanoproduct.

\section{Types of Nanomaterials Used in Cosmetic Formulations}

Due to its large surface area, the skin is an interesting administration route for several APIs. The advantages of topical drug delivery include the possibility to overcome the risk associated with the parenteral administration (e.g., pain, infection), avoidance of first pass metabolism associated with the oral administration of drugs, possibility to extend the treatment for longer timeframe which allows the use of drugs with small biological half-lives, and consequently reduce the gastrointestinal irritation promoted by the systemic administration. The major challenge encountered in the delivery of APIs through the skin is to overcome the different physiological layers of distinct polarity. Skin is known to protect the body from xenobiotics, which can be not only toxic agents and pathogens, but also drugs, 
while ensuring the expulsion of physiological fluids for homeostasis. As the permeation of the skin to the API compromises its absorption, the bioavailability of APIs administered topically is smaller in comparison to oral and intravenous routes [42]. Different types of nanoparticles have been proposed to overcome the difficulty encountered in skin administration of APIs.

\subsection{Nanoemulsions}

Nanoemulsions are thermodynamically stable systems with a translucent appearance and present particular rheological properties. They are defined as oil droplets stabilized by a combination of surfactant and co-surfactant in aqueous dispersion, preserving both the lightness and transparency $[43,44]$. Nanoemulsions are a common delivery system for the control release of nutraceuticals and APIs into deeper skin layers. Their lipophilic core makes nanoemulsions appropriate for the delivery of lipophilic compounds $[43,45,46]$. Another advantage is their small droplet size $(<200 \mathrm{~nm})$, which provides a large surface area in contact with the skin [3,47-49]. Nanoemulsions contribute also for the reduction of transepidermal water loss (TEWL) keeping the skin hydrated and thus more permeable to APIs [50]. Their high kinetic stability and high solubilization capacity make them an attractive nanocosmeceutical formulation. Different types of nanoemulsions, namely, oil-in-water $(\mathrm{o} / \mathrm{w})$, water-in-oil (w/o), or bicontinuous nanoemulsion, can be produced. Among the most popular cosmetic formulations used in e.g., sun care products, anti-aging or in moisturizing creams, are the nanogels obtained from concentrated $\mathrm{o} / \mathrm{w}$ nanoemulsions which generate a continuous network, useful to form a film onto the skin, avoiding TEWL, and increasing skin permeation to APIs. Several other marketed products (foams, creams, sprays, and liquids) are obtained from nanoemulsions e.g., deodorants, sunscreens, shampoos, lotions, nail polishers, conditioners, and hair sera [51].

\subsection{Solid Lipid Nanoparticles (SLN) and the Nanostructured Lipid Carriers (NLC)}

Among the different types of lipid nanoparticles, in the last decades, solid lipid nanoparticles (SLN) and the nanostructured lipid carriers (NLC) have emerged as promising nanosized delivery systems for skin administration of APIs $[16,17,52]$. Both SLN and NLC have a solid core of lipids stabilized by a suitable surfactant in aqueous dispersion. Their advantages are linked to their biocompatibility as they are composed of physiological lipids and with the capacity to modify the release profile of loaded APIs. While SLN are composed of one single solid lipid in their core, NLC are based on a blend of solid and liquid lipids offering higher loading capacity for lipophilic APIs over storage time. Scientific literature, however, reports an endless number of APIs (lipophilic, hydrophilic, poorly water-soluble drugs) loaded in both types of lipid nanoparticles, using different production techniques. As similar to nanoemulsions, the small size of SLN and NLC $(50-1000 \mathrm{~nm})$ increases their specific surface area, thereby providing an extended area in contact with the skin. The formation of a thin lipid film onto the surface with occlusive properties has also been reported to be an advantage for penetration of APIs into deeper skin layers. Together with their biocompatibility, biodegradability, and biotolerability $[25,27,28]$, these properties make SLN and NLC interesting carriers for cosmetic ingredients [53].

The solid core of SLN and NLC has been shown to act as a UV blocker, and a synergistic effect can be achieved when loading organic and/or inorganic sunscreens into the particles $[9,10]$. Besides, with the increase of the sun protection factor (SPF), the risk of adverse side effects can be reduced by the reduction of the amount of loaded sunscreen [54,55]. Fragrances and perfumes have also been loaded in lipid nanoparticles for extended release over the day [56].

AlZahabi et al. have developed NLC composed of prickly pear seed oil for topical delivery of retinyl palmitate [57]. To evaluate the permeation of vitamin A, ex vivo studies using rat skin have been run in vertical Franz diffusion cells. The higher concentration of surfactant and the lower viscosity of the tested NLC formulations were shown to improve skin permeation of the active.

In an ex vivo study with skin explants, Suter et al. confirmed that SLN loading a hydrophilic peptide with antioxidant capacity could stimulate NADPH quinone oxidoreductase, heme oxygenase-1, and peroxiredoxin-1 genes as an approach to protect cells from UV induced stress, as these are cell 
protecting enzymes [58]. The skin treated with the developed SLN formulation showed a significant reduction of the DNA damage in comparison to the placebo formulation.

Due to their lipophilic character, essential oils of cosmeceutical interest have been proposed as APIs in NLC [59]. Carbone et al. have formulated Rosmarinus officinalis L., Lavandula x intermedia "Sumian", Origanum vulgare subsp. hirtum, and Thymus capitatus essential oils into Softisan-NLC as a new approach to exploit the antibacterial, antifungal, antiviral, antioxidant, anticancer, immune-modulatory, analgesic, and anti-inflammatory activities of the oils [60]. Cell viability, anti-inflammatory, and anti-oxidant activities have been evaluated in vitro, confirming that NLC formulations can be fine-tuned for dermocosmetic applications. These Mediterranean oils can also be used to dissolve drugs in order to increase the loading capacity of NLC [15]. An antifungal NLC formulation, composed of clotrimazole and Lavandula or Rosmarinus as anti-proliferative agents, has been developed with the potential to be used as co-adjuvants in the treatment of non-tumoral proliferative dermal diseases [15]. A prolonged in vitro release of clotrimazole could be achieved while in vitro studies against Candida albicans, Candida krusei, and Candida parapsilosis confirmed the increased antifungal effect when using Lavandula or Rosmarinus oils in comparison to the non-loaded oil formulations. The anti-oxidant tocopherol has been proposed as the oily component of NLC for the loading of ketoconazole in the production of topical antifungal formulation [61-63]. Due to its sugar-lowering action, sucupira oil has been recently proposed as the oily component in NLC formulations [64].

Zielinska et al. formulated citral, alpha-pinene, geraniol, and limonene into glycerol monostearate lipid nanoparticles stabilized with poloxamer $[65,66]$. Despite their high volatility, all monoterpenes have been successfully loaded into the lipid matrices showing a modified release profile that can be exploited for antibacterial, antiviral, and antioxidant topical formulations. The loading of essential oils into lipid nanoparticles may also be useful to reduce the risk of cyto/genotoxic events $[25,27,28]$.

\subsection{Nanocrystals}

Drug nanocrystals are nanosized particles of APIs produced either by bottom-up or top down approaches [67]. Wet bead milling and high pressure homogenization are top-down methods claimed to be the main technologies used in the industry for the production of nanocrystals [68]. Nanocrystals are usually produced from poorly water-soluble drugs in aqueous surfactant dispersions to improve their solubility (e.g., by reducing their crystallinity) resulting in increased bioavailability [69]. The first cosmetic product containing nanocrystals was developed to improve the solubility of rutin and hesperidin, two glycosidic derivatives of flavonoids with antioxidant [70]. Other drugs, e.g., resveratrol, glibenclamide, quercetin, apigenin, curcumin, baicalin and baicalein, hesperetin, lutein, and silybin have been down-sized to produce nanocrystals [71,72].

\subsection{Dendrimers}

Dendrimers are highly branched nanostructures, consisting of a central core, branches, and terminal functional groups at the outer surface that govern their complexation with the payload [73]. As they show the capacity to modify the release profile of loaded APIs, they have been proposed as carriers in cosmetic formulations. Additional properties that make them interesting delivery systems are the monodispersity, polyvalence, stability, and the easy functionalization. Besides, during synthesis their molecular weight and size can be controlled, together with the degradation profile of the final assembly. Due to the dendrimers' versatility, both hydrophilic and hydrophobic APIs, either incorporated in the inner core or attached onto the surface [74]. The company L'Oréal Paris developed a formulation that contains hyperbranched polymers capable to form a film if deposited on a substrate which can be used in some cosmetics, for example, eye mascara or in the nail polish products [75]. L'Oréal has other formulation with dendrimers in the composition, as is the case for a tanning agent used in the artificial skin tanning. Another company, Unilever, developed dendrimers hydroxyl-functionalized to produce formulations to be used in different ways, such as sprays, gels, or lotions [76]. 


\subsection{Liposomes}

Liposomes are concentric phospholipid bilayers enclosing an aqueous core, making them suitable to load hydrophilic, lipophilic, and amphiphilic compounds [77-79]. Their use has been described for a set of administration routes, among which the topical delivery of APIs has been successfully exploited [80]. Their lipid composition makes liposomes biocompatible and biodegradable, with low risk of toxicity acting as penetration enhancers for the delivery of APIs into deeper skin layers (e.g., dermis). The risk of undergoing oxidation and/or hydrolysis, or even suffering drug leakage, are pointed out as the main disadvantages of liposomes.

The main component of liposomes is phosphatidyl choline, but several other lipids (e.g., glycerophospholipids, glycerolipids, phingophospholipids, ceramides, and cholesterol) can also be included in their composition. Cholesterol is commonly used to increase the rigidity of the vesicles and their encapsulation efficiency. Other compounds, e.g., tetracationic gemini Dabco-surfactants, have also been proposed for transdermal drug delivery [81]. By changing the lipid composition, the physicochemical properties of liposomes can be tailor-made to modify the delivery kinetics of APIs to the skin. For topical administration, liposomes can be further formulated into semi-solids such as creams, gels and ointments [82].

As happens with lipid nanoparticles, when liposomes are applied onto the skin, a thin lipid film is formed which can offer occlusive properties while avoiding water evaporation from the skin, keeping it moist and permeable to APIs. Liposomes have been produced with lipids from stratum corneum for the treatment of atopic dry skin [83]. Several anti-oxidants (e.g., superoxide dismutase, catalase, glutathione, $\mathrm{N}$-acetylcysteine, Coenzyme Q10, curcumin, resveratrol, tocopherols, retinoids, ascorbic acid, carotenoids) have been formulated in liposomes for anti-aging [84]. The antioxidants are also used to increase the physical and chemical stability of the vesicles when dispersed in water [85]. In addition, the antioxidant agents in their composition improve the stability of formulation also prevent the action of free radicals, pollution and oxidative stress, and improves skin health [42]. The liposomal anti-aging and antioxidant creams reduce the water loss of the skin, which reduces wrinkles and lines of expression, restoring the normal balance of the skin. Another clinical study has shown that flexible liposomes help in wrinkle reduction, have decreased the efflorescence in the treatment of acne and increase skin smoothness [86]. Liposomes have been formulated with chemical (benzophenone-3 [12], octyl methoxy cinnamate [87]) and physical ( $\mathrm{ZnO}$ and $\mathrm{TiO} 2$ [88]) sunscreens to offer UV protection in cosmetic formulations. Liposomes are reported for the delivery of vitamins, mainly in anti-aging creams, moisturizing cream, sunscreens, and for the treatment of hair loss [89]. Natural marine lipid-containing polyunsaturated fatty acids have anti-inflammatory properties [90], which is beneficial in inflammatory skin disorders, and promote the hydration and softening of the skin. The combination of plant extracts, and/or isolated natural compounds, with liposomes created a new class of healthcare products, becoming commonly used in the production of sunscreen formulations, anti-aging and moisturizing products, as they have antioxidant, anti-cellulite, and antimicrobial effects [82].

\subsection{Niosomes}

Niosomes have a similar structure to liposomes but are produced from nonionic surfactants (e.g., spans, tweens, alkyl amides, crown ester, polyoxyethylene alkyl ether, and steroid-linked surfactants). They can also contain cholesterol [91]. They are used to deliver both lipophilic and hydrophilic compounds, as well as poorly water-soluble drugs [92], providing an alternative over liposomes to overcome limited long-term stability and risk of oxidation of these latter [93]. Niosomes allow a controlled and targeted drug delivery, are osmotically active, and are non-immunogenic and nontoxic. Their biocompatibility and biodegradability profiles make them interesting delivery systems for topical administration with capacity to improve the dermal delivery of APIs as they reversibly reduce the skin barrier resistance [22]. Niosomes can, however, aggregate and suffer fusion, leaching, and hydrolysis of the loaded API, which compromises their shelf-life and loading capacity [94-96]. The first formulation containing niosomes was developed by the brand L'Oreal in 1970. Nowadays, there are some cosmetic 
and pharmaceuticals products in the market with niosomes in their composition, e.g., anti-wrinkle creams, skin whitenings, moisturizing creams, hair repairing shampoos, and conditioners [97].

\subsection{Metal Nanoparticles}

Metal nanoparticles are non-specific anti-bacterial agents of wide spectrum, that have been proposed as an alternative to classical antibiotics to overcome bacterial resistance [98]. The most common types of metal nanoparticles are based on silver, zinc oxide, gold, or copper. Their interest as ingredient of cosmetic formulations is attributed to their antifungal and antibacterial properties and can be used as preservatives. Besides, these particles are reported to be biocompatible, non-toxic, and chemically inert, and of high physicochemical stability [99]. Silver has been used as an antimicrobial agent for wound healing, and there are several available dressings containing $\mathrm{AgNO}_{3}[4,5]$.

Pulit-Prociak et al. produced cosmetic emulsions of silver (mean size 8-140 nm) and gold (mean size 13-99 nm) nanoparticles, and demonstrated their fungicidal activity [100]. The authors also showed that the skin permeability of silver and gold nanoparticles was dependent on their concentration in the cosmetic emulsions. A pectin-based silver nanocomposite film has been described for the transdermal delivery of donepezil [101]. The developed nanocomposite induced $<9 \%$ hemolysis in sheep erythrocytes, demonstrating to be non-toxic and biocompatible and with improved antimicrobial activity against Staphylococcus aureus and Escherichia coli.

Cosmetic products manufactured by L'Oreal with gold nanoparticles are already on the market [102], with the purpose of enhancing the firmness and elasticity of skin and delaying the aging process [103].

\subsection{Polymeric Nanoparticles}

Two distinct classical types of polymeric nanoparticles are described, i.e., nanospheres versus nanocapsules [104]. Nanospheres stand for a continuous matrix core in which the drug is dissolved or dispersed and from which it is released by diffusion. Nanocapsules comprise a liquid core (usually an oil dissolving the drug) surrounded by a polymeric layer which controls the release of drug. Polymeric nanoparticles can be obtained with a variety of sizes and morphologies, using natural or synthetic polymers as starting materials (top down production). Among synthetic polymers, the most commonly used are poly D,L-lactic-co-glycolic acid (PLGA), poly lactic acid (PLA), polycaprolactones, and polyacrylates. Alginate, chitosan, gelatin, starch, and albumin are examples of natural polymers. Polymeric nanoparticles are produced with the purpose of modifying the release profile of the loaded API, for targeted specific delivery and to increase the bioavailability of the payload. They show additional advantages of being physicochemically stable, non-toxic, and their degradation profile can be tailored-made. A variety of APIs (hydrophilic, lipophilic, amphiphilic) can be loaded into polymeric nanoparticles.

Tahir et al. proposed the formulation of PLGA nanoparticles loading ibuprofen and hydrocortisone into transdermal patches as an approach to reduce the risk of drug crystallization [105]. The drug flux through excised pig skin was also evaluated demonstrating that high drug loadings and high drug flux can be achieved by proper selection of the polymer [105].

Hydrogels containing pranoprofen-loaded PLGA nanoparticles have been produced by Abrego et al. [106]. The aim of the proposed formulation has been to increase the penetration of the drug into deeper skin layers in order to have effective anti-inflammatory and analgesic activities. PLGA nanoparticles showed sustained release of the payload. Both ex vivo studies in human skin and in vivo studies confirmed the added-value of using nanoparticles into semi-solids for the treatment of oedema, when compared to classical hydrogels [106].

Benzophenone-3 (BP-3) is an effective chemical UV filter of broad spectrum, but is known to trigger adverse reactions in vivo. To mitigate the risk of adverse side effects, its loading into different types of nanoparticles has been proposed [7,107]. Gilbert et al. evaluated the percutaneous absorption of BP-3 when administered as lipid versus polymeric nanoparticles. Poly- $\varepsilon$-caprolactone nanoparticles 
could significantly reduce the BP-3 skin permeation while showing the highest SPF [107]. A new sunscreen formulation based on benzophenone-3-poly(epsilon-caprolactone) nanocapsules has been produced by Barbosa et al. [7]. A non-Newtonian pseudoplastic semi-solid has been produced which showed no signs of irritation in HET-CAM test [7].

PLGA nanoparticles loading a xanthophyll carotenoid (astaxanthin) were tested for anti-photodamage in HaCaT cells [108]. The cytotoxicity assay, ROS scavenging and mitochondrial membrane potential assay highlighted the advantages of nanoparticles in improving anti-wrinkle and anti-oxidation effects of astaxanthin against the non-loaded carotenoid [108].

PLGA nanospheres containing ubiquinone have been developed for cosmetic application [109]. The drug permeation assay using iontophoresis via electric dermal administration on hairless mouse skin was evaluated. The authors reported that after iontophoresis, nanospheres were kept onto the horny layer of the skin, even after washing. Combining both PLGA nanospheres and iontophoresis may be an interesting approach for cosmetic use [109].

Oleanolic and ursolic acids are recognized triterpenoids with anti-cancer properties, and have been used in cosmetic formulations [110]. They have been proposed for the treatment of photoaged skin, as they show the ability to inhibit elastase thereby improving skin elasticity. The triterpenoids also show antioxidant, antimicrobial and anti-inflammatory activities. Their loading into PLGA nanoparticles has been done by Alvarado et al. and their cytotoxicity evaluated against HepG2 and Caco-2 cell lines [111]. The obtained data demonstrated the cytotoxic activity of these terpenoids against HepG2 and Caco-2 cells, which could be significantly reduced or eliminated when loaded into PLGA nanoparticles.

Chitosan nanoparticles have been produced for the sustained release of minoxidil sulphate to hair follicles for the treatment of hair loss [112]. Drug in vitro permeation studies through the skin, followed by selective drug recovery from the hair follicles, have shown a two-fold increase of drug concentration into hair follicles after $6 \mathrm{~h}$ when using chitosan nanoparticles in comparison to a control solution [112].

Due to their antimicrobial properties, chitosan films are proposed as wound dressings for the treatment of severe burns and chronic wounds [5]. A nanocomposite based on a blend of chitosan, poly(N-vinylpyrrolidone) and titanium dioxide was produced as wound dressing [113]. The developed dressing induced accelerated healing of open excision wounds in albino rat models.

Chitosan/tripolyphosphate (TPP) nanoparticles loading vegetable extracts from Ginkgo biloba L., Dimorphandra mollis Benth, Ruta graveolens, and Vitis vinifera L. known to be enriched with flavonoids were produced and the in vitro sun protection factor and the photostability profile of a cosmetic $\mathrm{o} / \mathrm{w}$ emulsion determined [8]. The developed emulsion based on chitosan-TPP nanoparticles was photostable, inducing a higher retention of rutin into the skin in a high extent.

\subsection{Carbon Nanotubes}

Carbon nanotubes (CNTs) are usually described as rolled graphene with $s p^{2}$ hybridization, with some chiral angles that involve the walls constituted by graphene, as a hexagonal lattice of carbon that originates the seamless cylindrical hollow fibers. Due to the pi-stacking, individual carbon nanotubes are aligned and present in the form of "ropes", of which diameter varies between 0.7 to $50 \mathrm{~nm}$ [114]. There are three types of CNTs, namely, the single-walled CNTs, doubled-walled CNTs, and multiwalled CNTs, and, independently of the type. The single-walled CNTs are the smaller and are constituted by a single graphene sheet that has a diameter about 1-2 $\mathrm{nm}$ and is present rolled upon itself. The double-walled CNTs have two concentric carbon nanotubes in their composition. While multiwalled CNTs are made up multiple layers of graphene tubes with a diameter ranges that vary from 2 to $50 \mathrm{~nm}$ [115]. The methods of production of CNTs are the arc discharge method, laser ablation, chemical vapor deposition method, and the flame synthesis method [116]. In the field of cosmetics, there are some patents that show the utility of CNTs in some products, namely in the hair colorants [26,27]. 


\subsection{Polymersomes}

Polymersomes are artificial vesicles made from the self-assembly of block copolymer amphiphiles resulting in a central cavity with a hydrophilic inner core surrounded by a lipophilic bilayer. Their mean diameter ranges vary from $50 \mathrm{~nm}$ to $5 \mu \mathrm{m}$ or higher [117]. Due to their composition, polymersomes are able to encapsulate both lipophilic and hydrophilic APIs. Polymersomes are very versatile, allowing the loading and release a diversity of of APIs (including proteins, peptides, enzymes, DNA, and RNA fragments) in diverse ways due to the introduction of different block copolymers with stimuli-responsive activity. The physicochemical composition and the molecular weight of polymersomes can be diverse depending on the final aim. Different polymersomes give different attributes, such as responsiveness to stimuli, different membrane thickness, and permeabilities [118]. Their membrane is very flexible, and for that reason polymersomes are able to target and control the release of APIs. When compared to the liposomes, polymersomes have a higher stability because of the presence of a thick and rigid bilayer in their structure [119]. There are some patents about polymersomes in the cosmetic field that prove their ability to improve the skin elasticity and to skin cell activation energy enhancement.

\subsection{Cubosomes}

Cubosomes are self-assembled bicontinuous cubic liquid crystalline particles. This phase is organized in two different water regions separated by surfactant bilayers enveloped into a three dimension which creates a strongly and cohesive structure [120]. Cubosomes are identified as the slightly spherical dots within a size range from 10 to $500 \mathrm{~nm}$, and they can load hydrophilic, hydrophobic, and amphiphilic APIs. These structures are easy to produce, can be used for controlled and targeted drug delivery, and are biodegradable $[120,121]$. Cubosomes are very attractive to be used in cosmetics, thus there are some companies studying their vantages and properties.

\section{Nanomaterials in Anti-Aging Formulations}

The use of nanomaterials in cosmetics is the fastest growing segment within the personal care industry. Table 1 lists several of these products that are already available on the market. Skin care cosmetic products act against the harmful effects of free radicals and pollution, and therefore improve skin texture and function, improving the maintenance of collagen structure and thus the strength of skin. Consequently, a healthier skin is obtained. Other skin structures that benefit from anti-aging cosmeceutical formulations are the keratins (fibrous structural protein, present in structures as hair, skin, nails) and elastin (extracellular matrix protein, necessary to maintain skin elasticity). Products as Agera Nano Eye Lift, incorporate growth factor peptides, retinol and retinyl palmitate that stimulate the production of collagen and epidermal cell proliferation, helping to smooth fine lines and wrinkles. Products from Bionova-Nano Skin Tech, designed to protect and treat the skin in various situations, uses co-encapsulations of various bioactive molecules (e.g., antioxidants, oils, proteins, drugs, sunscreens) according to the product aim. Sunscreens with zinc oxide and titanium dioxide in their composition are the most effective in skin protection, originating less greasy products, with less smell and transparent aspect [122]. Given that SLN, nanoemulsions, liposomes, and niosomes have the ability to keep the skin hydrated, due to the formation of a film of humectants that retain moisture for a longer period, they are widely used in moisturizing formulations. In the case of anti-aging cosmetics, the main products that are available consist in the use of nanocapsules, liposomes, nanosomes, and nanospheres for the loading of skin cosmeceuticals. Nanoformulations used in shampoos retain the moist within the cuticles increasing the contact time with scalp and hair follicles due to a formation of a protective film [32]. Conditioning nanocosmetic agents were created to increase the softness, shine, silkiness, gloss, and disentangling of hair. The newest developments in hair care use niosomes, microemulsion, nanoemulsion, nanospheres, and liposomes, aiming the repair of damaged cuticles, restoration of hair texture and gloss, and to keep the hair shinier, less greasy, and less brittle [123]. 
Table 1. Anti-aging products available to consumers and their respective purposes.

\begin{tabular}{cl}
\hline Brand-Product & \multicolumn{1}{c}{ Characteristics and Uses } \\
\hline Agera $^{\circledR}$-Nano Eye Lift & Anti-aging skin care. Make the skin around the eyes softer \\
\hline $\begin{array}{c}\text { Bionova-Nano Skin Tech Tennis Player } \\
\text { Sun and Wind Protection }\end{array}$ & $\begin{array}{l}\text { Confers UV protection, using nanocomplex of naturally } \\
\text { existing UV Chromophores and UV Protectant. Increase the } \\
\text { protection against the sun radiation. Widely used in dry skin } \\
\text { (nanocomplex of multiple antioxidants, oil, water-soluble } \\
\text { vitamins with their specific coenzymes) }\end{array}$ \\
\hline
\end{tabular}

Anti-aging power due to the incorporation of 24-karat gold

Chantecaille-Nano Gold Energizing Cream and silk bound, together with pullalan/algae and plantago extracts, and other natural antioxidants (vitamin E) and natural oils. Decrease significantly the lines, wrinkles, dullness and the dehydration. Antioxidant and anti-inflammatory activity.

Offers specialized hand care, for the treatment of age and/or sun spots, ageing skin, fine Lines and wrinkles.

StriVectin ${ }^{\mathrm{TM}}-$ Specialised Hand Care System

NanoExfoliate action (with thermo-active formula, exfoliate without causing redness or damage on the skin). Hand Cream ultra-concentrated to nourish, protect and hydrate the hand's skin (contains hyaluronic acid, UV blockers, etc).

Rosactive $^{\circledR}$ Phytoceutical Skin care-Biomixyl

Salcura ${ }^{\circledR}$ Natural Skin Therapy-e.g.,
Bioskin Zeoderm Skin Repair System

Bioskin Zeoderm Skin Repair System

Shakti $^{\circledR}$ Face and Body Resculpting
Cream $^{\mathrm{TM}}$

$\longrightarrow$ W

Nanoceuticals ${ }^{\mathrm{TM}}$ Citrus Mint Shampoo

Anti-aging line with several products designed to reduce wrinkles and lines by stimulating collagen production, using a bio-peptide complex and natural oils and extracts from several plants.

The products consist of natural colloidal solution delivery systems based on biotechnology and nanotechnology. Aimed to treat dry skin and irritation symptoms, uses natural extracts, oils and other ingredients. Used for the treatment of diseases, such as, eczema, psoriasis, dermatitis and other skin allergies.

With encapsulated black currant seed oil (also contains amino-acids, vitamin $\mathrm{C}$, oil from fragrant Bulgarian roses, etc.), to promote natural antibacterial and anti-inflammatory action, while conferring lifting and moisturizing to the skin from head to toe.

With nanoscale ingredients (in suspended nanoparticles), allow the scavenging of free radicals, the stimulation of the source energy, increased hydration, the balance of $\mathrm{pH}$, and others. Nanoparticles in the composition provide to the hair a healthy shine.

Make up products produced with resource to

Serge Lutens Blusher (Barneys New York $^{\circledR}$ ) Nano Dispersion technology nanotechnology. Due to the dispersion technology, this powder has excellent elasticity, extreme softness and light diffusion.

It is a re-mineralizing toothpaste (contains nano medical

Apagard®Royal-Sangi hydroxyapatite for protection against caries). Promotes oral health by preventing caries, remineralization and whitening using natural healing.

Several cosmetic products that are currently available on the market contain nanoemulsions in their composition, for encapsulating the cosmeceuticals, as is the case of Korres Hair Sun Protection Red Vine, a hair sunscreen, the Nanocream ${ }^{\circledR}$ from Sinerga and Nano Gel from Kemira, creating translucent micellar emulsions with particularly fine size-droplets with low viscosity. This type of nanoformulation is easily accepted by the consumer due to their sensorial properties, such as fast penetration, texture, and biophysical properties, i.e., high hydrating capacity. Nanoemulsions are particularly useful in sun 
care products, in moisturizing and anti-aging creams. The products described in Table 2 exemplify the advantages of a set of nanomaterials when compared to the conventional forms present on the market, as for example, coenzyme Q10 encapsulated in proniosomes have higher photo-protection when compared to the free coenzyme Q10.

Table 2. Example of cosmetic products containing nanomaterials currently available on the market.

\begin{tabular}{|c|c|c|}
\hline Nanomaterial & Active Ingredients and Applications & Brand/Producer \\
\hline Nanosomes $^{\mathrm{TM}}$ & $\begin{array}{l}\text { Plant extracts (e.g., Gingko biloba), oils (e.g., almond and } \\
\text { lavender) and natural compounds (caffeine, amino acids and } \\
\text { polyphenols). With high cationic charge density, enhances } \\
\text { the deposition of functional active ingredients and } \\
\text { fragrances at target site and reduces wash-off during rinse. } \\
\text { e.g., Viterol. A (Cream for Wrinkles and Expression Lines), } \\
\text { Revita }^{\circledR} \text { shampoo (Anti-hair loss, hair follicle stimulation) }\end{array}$ & DS Laboratories \\
\hline \multirow{5}{*}{ Liposomes } & $\begin{array}{l}\text { Coenzyme Q10, vitamins (A, C and E) and green tea extract. } \\
\text { Encapsulation using Rovisome } \\
\text { protection and antioxidant effect of the active ingredients. } \\
\text { e.g., Rovisome ACE Plus, Rovisome Defence, Rovisome Q10 }\end{array}$ & $\begin{array}{l}\text { Rovi Cosmetics } \\
\text { International GmbH }\end{array}$ \\
\hline & $\begin{array}{l}\text { Coenzyme Q10. Enhances antioxidant, anti-wrinkle and } \\
\text { penetration properties, as well as collagen and elastin } \\
\text { production of connective tissue. e.g., Ageless Face Firming } \\
\text { Serum, Ageless Anti-Wrinkle Serum }\end{array}$ & I-Wen Naturals \\
\hline & $\begin{array}{l}\text { Natural extracts and oils (Chondrus crispus, Prunus armeniaca, } \\
\text { Aloe barbadensis, Symphytum officinale, Rosa damascena). } \\
\text { Liposome encapsulation improves natural products delivery } \\
\text { to target site, with higher antioxidant activity and skin } \\
\text { hydration. e.g., Liposome Concentrate }\end{array}$ & Russell Organics \\
\hline & $\begin{array}{l}\text { Vitamin E, hyaluronic acid, super oxide dismutase (SOD) } \\
\text { and sunflower oil. The use of encapsulated vitamin E, SOD } \\
\text { and hyaluronic acid increases skin protection to sun damage } \\
\text { and oxidative stress. Skin rejuvenation in enhanced. e.g., } \\
\text { Liposome Face and Neck Lotion }\end{array}$ & Clinicians Complex \\
\hline & $\begin{array}{l}\text { Liposomes formulation containing ginseng to mitigate skin } \\
\text { aging signs. E.g., Anti-Age Response Cream Simply Man } \\
\text { Match }\end{array}$ & $\begin{array}{l}\text { Nouvelle, HSA }{ }^{\circledR} \\
\text { cosmetics }\end{array}$ \\
\hline \multirow{2}{*}{ SLN and NLC } & $\begin{array}{l}\text { Includes plant extracts and oils, that promote skin } \\
\text { regeneration and provide anti-inflammatory and anti-scaling } \\
\text { activities. E.g., Phyto NLC Active Cell Repair }\end{array}$ & Sirehemas $^{\mathrm{TM}}$ \\
\hline & $\begin{array}{l}\text { Q10, hemp and macadamia nut oils, oil, Edelweiss extract. } \\
\text { The encapsulation improved skin's elasticity and } \\
\text { regeneration. E.g., Xcelent Uplift Q10 }\end{array}$ & Dr. Rimpler \\
\hline \multirow[t]{2}{*}{ Nanoemulsion } & $\begin{array}{l}\text { Vitamin E and B3, provitamin B5. Enhanced penetration of } \\
\text { the active ingredients, that provide anti-pollution and } \\
\text { enhance skin's hydration and regeneration. E.g., } \\
\text { Bepanthol-Protect Facial Cream Ultra }\end{array}$ & Bayer HealthCare \\
\hline & $\begin{array}{l}\text { UVA and UVB filters, loaded in transparent cationic } \\
\text { Nanoemulsions, for hair protection. E.g., Nano-lipobelle }{ }^{\mathrm{TM}}\end{array}$ & $\begin{array}{l}\text { Mibelle Biochemistry, } \\
\text { Switzerland }\end{array}$ \\
\hline
\end{tabular}


Table 2. Cont.

\begin{tabular}{|c|c|c|}
\hline Nanomaterial & Active Ingredients and Applications & Brand/Producer \\
\hline \multirow{2}{*}{$\begin{array}{l}\text { Nanocomplex with } \\
\mathrm{TiO}_{2} \text { and } \mathrm{ZnO}\end{array}$} & $\begin{array}{l}\text { Contain Zinc oxide particles that act as UV radiation } \\
\text { blockers for sun protection. E.g., Sheer Zinc Dry-Touch } \\
\text { Sunscreen Broad Spectrum SPF 50 }\end{array}$ & Neutrogena ${ }^{\circledR}$ \\
\hline & $\begin{array}{l}\text { Contains iron oxide, titanium dioxide and plant extracts and } \\
\text { vitamins. Bronze mineral pigments in its composition } \\
\text { provide sun tan effect. E.g., Instant bronze body butter. }\end{array}$ & Mineral Fusion ${ }^{\circledR}$ \\
\hline \multirow[t]{2}{*}{ Gold nanoparticles } & $\begin{array}{l}\text { Composed of } 24 \mathrm{k} \text { gold and silk bounded together, botanical } \\
\text { (extracts and oils) and plant stem cell extracts, promoting } \\
\text { antioxidant, smoothing, clarity and luminosity properties. } \\
\text { with anti-aging, anti-wrinkle and anti-redness properties. } \\
\text { Skin care products (e.g., Nano Gold Energizing Cream and } \\
\text { Nano Gold Energizing Eye Serum) }\end{array}$ & Chantecaille \\
\hline & $\begin{array}{l}\text { The active ingredients include gold powder, plant extracts } \\
\text { (coffee Seed (Coffee arabica), Aloe barbadensis, Cucurbita pepo } \\
\text { (Pumpkin) seed), vitamins (A, C and E) and hyaluronic acid. } \\
\text { Skin care product with anti-aging properties. E.g., Nano } \\
\text { Gold Anti-Aging Lifting Serum }\end{array}$ & Nuvoderm \\
\hline \multirow[b]{2}{*}{ Nanospheres } & $\begin{array}{l}\text { Plant extracts and oils (olive, Canadian Willowherb }{ }^{\mathrm{TM}} \text {, green } \\
\text { tea), vitamin E and hyaluronic acid. Provide anti-wrinkle } \\
\text { activity, anti-inflammatory activity and stimulate fibroblasts } \\
\text { and collagen production. e.g., Eye Tender }{ }^{\circledR}\end{array}$ & Kara Vita \\
\hline & $\begin{array}{l}\text { Contain natural products (soy firming agent), vitamin } \mathrm{E} \text { and } \\
\text { UVA/UVB filters. Nanospheres provide a sustained release } \\
\text { of the active ingredients. The formulation promotes } \\
\text { moisturizing and anti-inflammatory activities as well as skin } \\
\text { repair on scarred tissues and UV radiation protection. The } \\
\text { photo-reflecting agent confers radiance to the complexion. } \\
\text { E.g., DNA Filler Intense Cream }\end{array}$ & CellAct Switzerland \\
\hline
\end{tabular}

The environmental effects on the skin and the genetic programming cause the first signals of aging [124]. The aging processes occur intrinsically at different rates and differ among individuals. It depends on genetic regulation, metabolism, lifestyle, and the formation of toxic products as part of metabolism processes [125]. The major factors that influence the aging process are basically split into: (i) the biological factors, that are intrinsically determined by the genetic and are unchangeable and by metabolism; (ii) the environmental factors, that depend on lifestyle (e.g., time of exposure to the sunlight; nicotine habits, etc.); the environment pollution; (iii) the mechanical aging, which is the response to the muscle movements; (iv) miscellaneous factors, such as diet, sleeping habits, mental health, and so on [126].

Aging is a process that starts with a decrease of cell renewal together with alterations in external matrix protein integrity [126]. Therefore, as intrinsic aging progresses, a decrease in subdermal fat tissues is promoted together with elastolysis and modest changes in collagen organization, which leads to the loss of support, causing sagging of the skin.

On the other hand, extrinsic aging occurs due to environmental factors, stress episodes and the use of products that compromise skin integrity. Environmental factors are essentially climate conditions, e.g., sun exposure, air pollution, the nicotine habits, and so on. By promoting the formation of free radicals, UV radiation is deleterious to collagenous tissues and also to elastin. The decrease of cell turnover, of water content, the hyperpigmentation and the occurrence of wrinkles are signals of skin aging [126]. As strategies against photo-damage cascade episodes, the most common actions block UV-radiation penetration using sunscreens, both physical or chemical, decreasing and/or preventing inflammation by using anti-inflammatory products and promoting the removal of reactive oxygen species using antioxidants [127].

In the cosmetic products, different APIs can be used to prevent, delay, and, if possible, treat aging skin. These include antioxidants (e.g., vitamins, polyphenols, phenolic acids), growth factors, retinoids 
(derivatives of vitamin A), sun filters, natural ingredients, such as herbal ingredients, natural acids and their derivatives, oils, and others [125]. It has been demonstrated that nanomaterials can be used to increase the effectiveness and to reduce the degradability of the administrated APIs.

Free radicals are noxious to the skin because they induce lipid peroxidation, DNA damage, and inflammation, events deeply connect to aging [127]. Vitamins and coenzymes with antioxidant activity include vitamin $\mathrm{E}$ (alpha-tocopherol), vitamin C (ascorbic acid), vitamin $\mathrm{K}$, beta-carotene (vitamin A precursor), coenzyme $Q$, nicotinamide, and lipoic acid. As enzymatic antioxidants, it can be pointed to the glutathione peroxidase, the superoxide dismutase, and catalase [35]. Some substances involved in cell regulation are biological growth factors and, for example, kinetin (a cytokinin, a plant growth hormones), was shown to have potent antioxidant capacity, capable of protecting the skin against the oxidative damage caused by sunlight rays, is commonly used in cosmetic formulations as anti-aging [125]. Growth factors are also included in cosmetics to stimulate collagen and elastin synthesis to repair the dermal extracellular matrix.; being the most common the epidermal growth factor (EGF), transforming growth factor (TGF), platelet-derived growth factor (PDGF), fibroblast growth factor (FGF), insulin growth factor (IGF) and interleukin $[51,128]$. Herbal extracts and essential oils are another source of active cosmetic ingredients used against skin aging $[15,29,31,59,60,66,129-132]$. The possibility to administer these natural products either as oral or as an active ingredient in topical formulations is an advantage. Over centuries, antioxidant, anti-inflammatory, anti-carcinogenic, and anti-aging properties have been attributed to plants and their components [133-136].

Regarding retinoids (which comprise vitamin A (retinol) and its natural derivatives), these are the most studied anti-aging compounds, as they stimulate the synthesis of collagen, reducing fine lines and wrinkles. Retinol is widely used due to its effect against photo-damage and in the prevention and treatment of cellulite as it also stimulates the production of new blood vessels. Tretinoin, including isotretinoin, retinaldehyde, and tazarotene, are commonly used in photo-aging. Retinoids have benefits in wrinkles attenuation, in the decrease of roughness and to treat and prevent hyperpigmentation [137].

Hyaluronic acid promotes skin firmness and helps to maintain the original structure of the skin. With the progress in photo-damaged (and age damaged) skin there is less production of hyaluronic acid, which promotes the formation of wrinkles. The topical administration of hyaluronic acid provides the moisturizing needed to attenuates wrinkles [138].

Other group of bioactive compounds include alpha hydroxy acids (AHAs), which consist of a carboxylic acid substituted with a hydroxyl group on the adjacent carbon, can be natural or of synthetic origin. AHAs are derived from plant or animal origin, and some of them are used in cosmetic industry, namely glycolic acid (from sugar cane), citric acid (from citrus fruits), hydroxycaprylic acid (from animals), lactic acid (from lactose or other carbohydrates), and others. In the treatment of photo-damaged skin, AHAs have an effective action if incorporated in the proper formulation, and with the right $\mathrm{pH}$, namely glycolic acid, lactic acid, and citric acid were shown to increase collagen synthesis and increased skin thickness without detectable inflammation. Combination of AHAs and retinoic acid increases the effectiveness of retinoic acid, although in some cases, the combination of these increased the irritation in the local of application, which is a disadvantage [139]. Another active ingredient used in the treatment of photo-damaged skin, and as an anti-aging product, is salicylic acid, a beta-hydroxy acid (BHA), which, among the natural products, is one of the most used. Salicylic acid is widely used in photo-aging treatments, as peeling agents (in more than $30 \%$ of the cosmetics to this aim), it is used for exfoliation, it reduces inflammation, unclogs pores, and controls acne. Formulations containing salicylic acid are more patient-friendly as they have reduced irritancy levels when compared to AHAS formulation [140].

The recently formulated sunscreens not only prevent the UVs from reach the deepest layers of skin, but also have the ability to repair the sun-damaged skin. Sunscreens protect the skin by covering this organ and preventing sunburns as well as erythema caused by the action of UV rays. A prolonged exposure to UV radiation promotes loss of water, leading to dehydration [141]. When studying topical administration as an efficient route to apply active ingredients to prevent skin aging, it is necessary to 
take into account two principles: assure that the active ingredient reaches the site of action with the right concentration; and that the active cosmetic ingredients are available in the local of action over a certain period of time at the required concentration [142].

Other types of nanomaterials being currently exploited for the delivery of cosmeceuticals and pharmaceuticals are nanolignins and nanocelluloses. Chitin and lignin are by-products of plant biomass and can be used as starting materials for the production of eco-friendly, biocompatible pharmaceuticals and cosmeceuticals. Their high antibacterial, anti-inflammatory, cicatrizing, and anti-aging activities have been described at the nanoscale. Danti et al. have produced microcapsules composed of chitin nanofibrlis (positively charged) and nanolignin (negatively charged) for the loading of glycyrrhetinic acid [143]. The obtained microcapsules were shown to downregulate proinflammatory cytokines IL-1-alpha (IL-1 $\alpha$ ), IL-1-beta (IL-1 $\beta$ ), IL-6, IL-8, and TNF-alpha and upregulate antimicrobial peptide human beta defensin-2. The tested human mesenchymal stromal cell line remained viable while their contact with microcapsules did not modify the osteo-differentiation capability of the cells. The authors postulate that the developed formulation may be useful for the delivery of biomolecules for skin care and regeneration, showing anti-inflammatory activity and cytocompatibility [143].

Within the field of anti-aging, biodegradable non-woven tissues have been recently proposed for the site-specific release of active ingredients into deeper skin layers. Morganti et al. have used polysaccharide natural fibers composed of chitin nanofibrils and nanochitin for the production of biofunctional textiles [144]. The developed tissues were shown to mimic the skin extra cellular matrix being suitable for skin repair and for anti-aging and were also proposed for food formulation.

Nanocellulose, in particular cellulose nanocrystals and nanofibrillated cellulose, are reported to exhibit attractive properties for use in cosmetic, pharmaceutical, and food products. They are derived from the most widespread and renewable biopolymer-cellulose, showing remarkable chemical and physical properties that can be exploited for the development of new formulations [145]. Chitosan nanocellulose composites have been proposed for both skin tissue engineering and wound dressings as they exhibit biocompatibility, cell adhesion, 3D nanoporous structure, mechanical strength, and high porosity [146], with capacity to load a range of active ingredients. Nanocellulose films have been produced with titanium dioxide nanoparticles for their high refractive index and UV absorbing properties [147]. High transparency in hybrid films have been produced with extraordinary optical and mechanical properties and high transmittances in the visible region. The authors postulate the potential use of nanocellulose-based hybrids as transparent coatings with UV absorbing properties.

Figure 2 summarizes examples of nanomaterials used for the loading of several APIs and their application purposes. 


\section{Active pharmaceutical ingredient \\ Nanomaterials Application purpose}

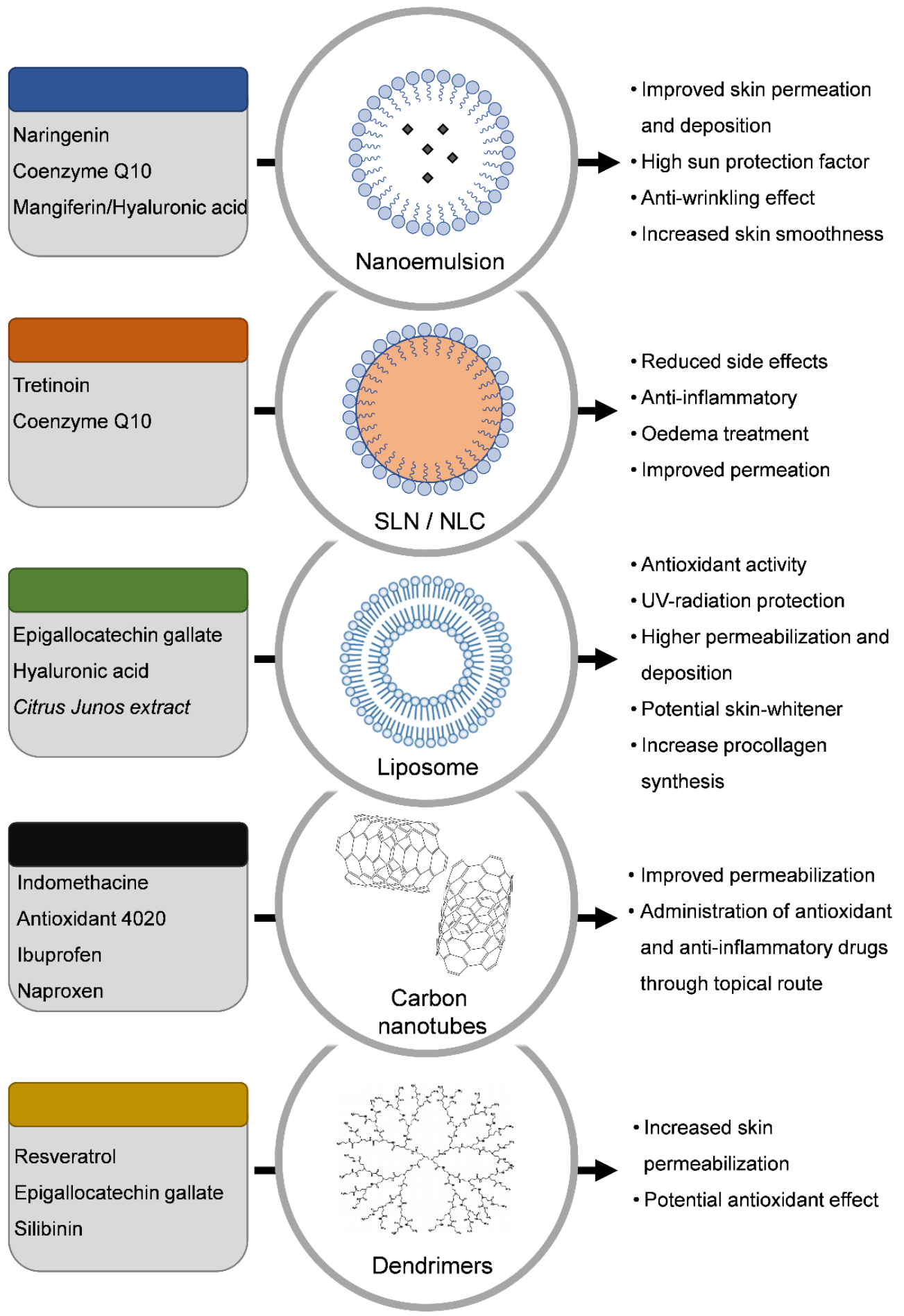

Figure 2. Examples of nanomaterials used for the encapsulation of several active pharmaceutical ingredients and their application purposes.

\section{Conclusions}

Nanomaterials-based products are increasingly growing and reaching different markets over the last few decades, e.g., dermatology, cosmetics, and pharmaceutics. Several types of nanomaterials, e.g., 
liposomes, niosomes, SLN, NLC, gold nanoparticles, polymeric nanoparticles, and nanoemulsions, have been proposed for the delivery of cosmetic ingredients, as they are produced from biocompatible materials. The developed nanocosmeceutical shows enhanced stability, biocompatibility, and has a prolonged action and capacity to improve skin delivery of the payload. Nanoemulsions are an example of great improvements in the cosmetic field. Their use in personal care products benefits from the possibility to have a controlled delivery of cosmeceuticals, together with a more uniform delivery onto the skin through the formation of a thin film. Skin aging is a complex process that can be caused by endogenous and/or exogenous factors. Almost $90 \%$ of the skin aging processes are caused by the exposure to the UV radiation. The lifestyle is another factor that influences the progression of skin aging (e.g., stress, smoking, sleeping, and alcoholic habits), also the environmental factors (e.g., pollution), malnutrition, and so on. The first signs of skin aging include dry aspect, loss of skin elasticity, and the appearance of wrinkles. It is nowadays possible to prevent and/or delay the first signs of skin aging. The conventional topical formulations (e.g., solution, suspensions, gels, emulsions, powder, and aerosols) are acceptable for topical delivery of active ingredients; however, all these formulations have some limitations and can compromise the safety and/or effectiveness of the treatment. A range of nanomaterials for the delivery of active ingredients have been developed to overcome these limitations. The continuous development of skin products with active ingredients making use of nanomaterials offers innovative alternatives in health and cosmetic care sectors, with beneficial effects to the industry and society.

Author Contributions: E.B.S., A.R.F., A.M.S., C.M.-G., T.E.C., and A.D. have written the original manuscript. E.B.S., A.M.S. and A.S. have reviewed and edited the manuscript. M.L., S.B.S., C.M.-G., T.E.C., and A.D. have contributed for the building up of the figures and tables. E.B.S., A.M.S., and A.S. have conceptualized, structured, reviewed and supervised the literature research. All authors have made a substantial contribution to this review. All authors have read and agreed with the publication of the manuscript.

Funding: The authors acknowledge the financial support received from Portuguese Science and Technology Foundation (FCT/MCT) and from European Funds (PRODER/COMPETE) for the projects M-ERA-NET/0004/2015-PAIRED and UIDB/04469/2020 (strategic fund) co-financed by FEDER, under the Partnership Agreement PT2020. The FCT grant to CMG (SFRH/BD/145855/2019) and project PEst-OE/UID/AGR/04033/2019 (CITAB strategic fund) are also acknowledged. The authors acknowledge the support of the research project: Nutraceutica come supporto nutrizionale nel paziente oncologico, CUP: B83D18000140007.

Conflicts of Interest: The authors declare no conflict of interest.

\section{References}

1. Oberdörster, G.; Oberdörster, E.; Oberdörster, J. Nanotoxicology: An emerging discipline evolving from studies of ultrafine particles. Environ. Health Perspect. 2005, 113, 823-839. [CrossRef] [PubMed]

2. Souto, E.B.; Dias-Ferreira, J.; Oliveira, J.; Sanchez-Lopez, E.; Lopez-Machado, A.; Espina, M.; Garcia, M.L.; Souto, S.B.; Martins-Gomes, C.; Silva, A.M. Trends in Atopic Dermatitis-From Standard Pharmacotherapy to Novel Drug Delivery Systems. Int. J. Mol. Sci. 2019, 20, 5659. [CrossRef] [PubMed]

3. Severino, P.; Fangueiro, J.F.; Ferreira, S.V.; Basso, R.; Chaud, M.V.; Santana, M.H.; Rosmaninho, A.; Souto, E.B. Nanoemulsions and nanoparticles for non-melanoma skin cancer: Effects of lipid materials. Clin. Transl. Oncol. 2013, 15, 417-424. [CrossRef]

4. Souto, E.B.; Ribeiro, A.F.; Ferreira, M.I.; Teixeira, M.C.; Shimojo, A.A.M.; Soriano, J.L.; Naveros, B.C.; Durazzo, A.; Lucarini, M.; Souto, S.B.; et al. New Nanotechnologies for the Treatment and Repair of Skin Burns Infections. Int. J. Mol. Sci. 2020, 21, 393. [CrossRef] [PubMed]

5. Barbosa, G.P.; Debone, H.S.; Severino, P.; Souto, E.B.; da Silva, C.F. Design and characterization of chitosan/zeolite composite films-Effect of zeolite type and zeolite dose on the film properties. Mater. Sci. Eng. C 2016, 60, 246-254. [CrossRef] [PubMed]

6. Cefali, L.C.; Ataide, J.A.; Fernandes, A.R.; Sousa, I.M.O.; Goncalves, F.; Eberlin, S.; Davila, J.L.; Jozala, A.F.; Chaud, M.V.; Sanchez-Lopez, E.; et al. Flavonoid-Enriched Plant-Extract-Loaded Emulsion: A Novel Phytocosmetic Sunscreen Formulation with Antioxidant Properties. Antioxidants (Basel) 2019, 8, 443. [CrossRef] [PubMed] 
7. Barbosa, T.C.; Nascimento, L.E.D.; Bani, C.; Almeida, T.; Nery, M.; Santos, R.S.; Menezes, L.R.O.; Zielinska, A.; Fernandes, A.R.; Cardoso, J.C.; et al. Development, Cytotoxicity and Eye Irritation Profile of a New Sunscreen Formulation Based on Benzophenone-3-poly(epsilon-caprolactone) Nanocapsules. Toxics 2019, 7, 51. [CrossRef]

8. Cefali, L.C.; Ataide, J.A.; Eberlin, S.; da Silva Goncalves, F.C.; Fernandes, A.R.; Marto, J.; Ribeiro, H.M.; Foglio, M.A.; Mazzola, P.G.; Souto, E.B. In vitro SPF and Photostability Assays of Emulsion Containing Nanoparticles with Vegetable Extracts Rich in Flavonoids. AAPS Pharmscitech 2018, 20, 9. [CrossRef]

9. Xia, Q.; Saupe, A.; Muller, R.H.; Souto, E.B. Nanostructured lipid carriers as novel carrier for sunscreen formulations. Int. J. Cosmet. Sci. 2007, 29, 473-482. [CrossRef]

10. Souto, E.B.; Anselmi, C.; Centini, M.; Muller, R.H. Preparation and characterization of n-dodecyl-ferulate-loaded solid lipid nanoparticles (SLN). Int. J. Pharm. 2005, 295, 261-268. [CrossRef]

11. Osmond-McLeod, M.J.; Oytam, Y.; Rowe, A.; Sobhanmanesh, F.; Greenoak, G.; Kirby, J.; McInnes, E.F.; McCall, M.J. Long-term exposure to commercially available sunscreens containing nanoparticles of $\mathrm{TiO}_{2}$ and $\mathrm{ZnO}$ revealed no biological impact in a hairless mouse model. Part Fibre Toxicol. 2016, 13, 44. [CrossRef] [PubMed]

12. Severino, P.; Moraes, L.F.; Zanchetta, B.; Souto, E.B.; Santana, M.H.A. Elastic liposomes containing benzophenone-3 for sun protection factor enhancement. Pharm. Dev. Technol. 2012, 17, 661-665. [CrossRef] [PubMed]

13. Singhal, M.; Khanna, S.; Nasa, A. Cosmeceuticals for the skin: An overview. Asian J. Pharm. Clin. Res. 2011, $4,1-6$.

14. Ahmadi Ashtiani, H.R.; Bishe, P.; Lashgari, N.; Nilforoushzadeh, M.A.; Zare, S. Liposomes in Cosmetics. J. Ski. Stem Cell 2016, 3, e65815. [CrossRef]

15. Carbone, C.; Teixeira, M.D.C.; Sousa, M.D.C.; Martins-Gomes, C.; Silva, A.M.; Souto, E.M.B.; Musumeci, T. Clotrimazole-Loaded Mediterranean Essential Oils NLC: A Synergic Treatment of Candida Skin Infections. Pharmaceutics 2019, 11, 231. [CrossRef] [PubMed]

16. Souto, E.B.; Doktorovova, S. Chapter 6-Solid lipid nanoparticle formulations pharmacokinetic and biopharmaceutical aspects in drug delivery. Methods Enzymol. 2009, 464, 105-129. [CrossRef]

17. Souto, E.B.; Baldim, I.; Oliveira, W.P.; Rao, R.; Yadav, N.; Gama, F.M.; Mahant, S. SLN and NLC for topical, dermal and transdermal drug delivery. Expert Opin. Drug Deliv. 2020, 17, 357-377. [CrossRef]

18. Saha, R. Cosmeceuticals and herbal drugs: Practical uses. Int. J. Pharm. Sci. Res. 2012, 3, 59.

19. Dureja, H.; Kaushik, D.; Gupta, M.; Kumar, V.; Lather, V. Cosmeceuticals: An emerging concept. Indian J. Pharmacol. 2005, 37, 155. [CrossRef]

20. Srinivas, K. The current role of nanomaterials in cosmetics. J. Chem. Pharm. Res. 2016, 8, 906-914.

21. Brandt, F.S.; Cazzaniga, A.; Hann, M. Cosmeceuticals: Current trends and market analysis. Semin. Cutan. Med. Surg. 2011, 30, 141-143. [CrossRef] [PubMed]

22. Kaul, S.; Gulati, N.; Verma, D.; Mukherjee, S.; Nagaich, U. Role of Nanotechnology in Cosmeceuticals: A Review of Recent Advances. J. Pharm. 2018, 2018, 3420204. [CrossRef] [PubMed]

23. Souto, E.B.; Silva, G.F.; Dias-Ferreira, J.; Zielinska, A.; Ventura, F.; Durazzo, A.; Lucarini, M.; Novellino, E.; Santini, A. Nanopharmaceutics: Part I-Clinical Trials Legislation and Good Manufacturing Practices (GMP) of Nanotherapeutics in the EU. Pharmaceutics 2020, 12, 146. [CrossRef] [PubMed]

24. Souto, E.B.; Dias-Ferreira, J.; Shegokar, R.; Durazzo, A.; Santini, A. Ethical issues in research and development of nanoparticles. In Drug Delivery Aspects; Shegokar, R., Ed.; Drug Delivery Trends; Elsevier: AE Amsterdam, The Netherlands, 2020; Volume 3, Chapter 7.

25. Doktorovova, S.; Kovacevic, A.B.; Garcia, M.L.; Souto, E.B. Preclinical safety of solid lipid nanoparticles and nanostructured lipid carriers: Current evidence from in vitro and in vivo evaluation. Eur. J. Pharm. Biopharm. 2016, 108, 235-252. [CrossRef]

26. Doktorovova, S.; Shegokar, R.; Rakovsky, E.; Gonzalez-Mira, E.; Lopes, C.M.; Silva, A.M.; Martins-Lopes, P.; Muller, R.H.; Souto, E.B. Cationic solid lipid nanoparticles (cSLN): Structure, stability and DNA binding capacity correlation studies. Int. J. Pharm. 2011, 420, 341-349. [CrossRef]

27. Doktorovova, S.; Silva, A.M.; Gaivao, I.; Souto, E.B.; Teixeira, J.P.; Martins-Lopes, P. Comet assay reveals no genotoxicity risk of cationic solid lipid nanoparticles. J. Appl. Toxicol. 2014, 34, 395-403. [CrossRef] 
28. Doktorovova, S.; Souto, E.B.; Silva, A.M. Nanotoxicology applied to solid lipid nanoparticles and nanostructured lipid carriers-a systematic review of in vitro data. Eur. J. Pharm. Biopharm. 2014, 87, 1-18. [CrossRef]

29. Durazzo, A.; Lucarini, M.; Souto, E.B.; Cicala, C.; Caiazzo, E.; Izzo, A.A.; Novellino, E.; Santini, A. Polyphenols: A concise overview on the chemistry, occurrence, and human health. Phytother. Res. 2019, 33, 2221-2243. [CrossRef]

30. Pimentel-Moral, S.; Teixeira, M.C.; Fernandes, A.R.; Arraez-Roman, D.; Martinez-Ferez, A.; Segura-Carretero, A.; Souto, E.B. Lipid nanocarriers for the loading of polyphenols-A comprehensive review. Adv. Colloid Interface Sci. 2018, 260, 85-94. [CrossRef]

31. Salehi, B.; Venditti, A.; Sharifi-Rad, M.; Kregiel, D.; Sharifi-Rad, J.; Durazzo, A.; Lucarini, M.; Santini, A.; Souto, E.B.; Novellino, E.; et al. The Therapeutic Potential of Apigenin. Int. J. Mol. Sci. 2019, $20,1305$. [CrossRef]

32. Rosen, J.; Landriscina, A.; Friedman, A.J. Nanotechnology-based cosmetics for hair care. Cosmetics 2015, 2, 211-224. [CrossRef]

33. Sundari, P.T.; Anushree, H. Novel delivery systems: Current trend in cosmetic industry. Eur. J. Pharm. Med. Res. 2017, 4, 617-627.

34. Pereira, L.; Dias, N.; Carvalho, J.; Fernandes, S.; Santos, C.; Lima, N. Synthesis, characterization and antifungal activity of chemically and fungal-produced silver nanoparticles against T richophyton rubrum. J. Appl. Microbiol. 2014, 117, 1601-1613. [CrossRef] [PubMed]

35. Doktorovova, S.; Santos, D.L.; Costa, I.; Andreani, T.; Souto, E.B.; Silva, A.M. Cationic solid lipid nanoparticles interfere with the activity of antioxidant enzymes in hepatocellular carcinoma cells. Int. J. Pharm. 2014, 471, 18-27. [CrossRef] [PubMed]

36. Silva, A.M.; Martins-Gomes, C.; Fangueiro, J.F.; Andreani, T.; Souto, E.B. Comparison of antiproliferative effect of epigallocatechin gallate when loaded into cationic solid lipid nanoparticles against different cell lines. Pharm. Dev. Technol. 2019, 24, 1243-1249. [CrossRef] [PubMed]

37. Daliu, P.; Santini, A.; Novellino, E. From pharmaceuticals to nutraceuticals: Bridging disease prevention and management. Expert Rev. Clin. Pharm. 2019, 12, 1-7. [CrossRef]

38. Salehi, B.; Ata, A.; Anil Kumar, V.N.; Sharopov, F.; Ramírez-Alarcón, K.; Ruiz-Ortega, A.; Abdulmajid Ayatollahi, S.; Tsouh Fokou, P.V.; Kobarfard, F.; Amiruddin Zakaria, Z.; et al. Antidiabetic potential of medicinal plants and their active components. Biomolecules 2019, 9, 551. [CrossRef]

39. Santini, A.; Cammarata, S.M.; Capone, G.; Ianaro, A.; Tenore, G.C.; Pani, L.; Novellino, E. Nutraceuticals: Opening the debate for a regulatory framework. Br. J. Clin. Pharm. 2018, 84, 659-672. [CrossRef]

40. Santini, A.; Novellino, E. Nutraceuticals-shedding light on the grey area between pharmaceuticals and food. Expert Rev. Clin. Pharm. 2018, 11, 545-547. [CrossRef]

41. Bhadoriya, S.S.; Mangal, A.; Madoriya, N.; Dixit, P. Bioavailability and bioactivity enhancement of herbal drugs by "Nanotechnology": A review. J. Curr. Pharm. Res. 2011, 8, 1-7.

42. Dokhani, A.; Amini, J.; Gortzi, O.; Danaei, M.; Mozafari, M.R.; Maherani, B. Enhanced Efficacy and Bioavailability of Skin-Care Ingredients Using Liposome and Nano-liposome Technology. Mod. Appl. Bioequiv. Availab. 2017, 2, 555584.

43. Alvarado, H.L.; Abrego, G.; Souto, E.B.; Garduno-Ramirez, M.L.; Clares, B.; Garcia, M.L.; Calpena, A.C. Nanoemulsions for dermal controlled release of oleanolic and ursolic acids: In vitro, ex vivo and in vivo characterization. Colloids Surf. B Biointerfaces 2015, 130, 40-47. [CrossRef] [PubMed]

44. Clares, B.; Calpena, A.C.; Parra, A.; Abrego, G.; Alvarado, H.; Fangueiro, J.F.; Souto, E.B. Nanoemulsions (NEs), liposomes (LPs) and solid lipid nanoparticles (SLNs) for retinyl palmitate: Effect on skin permeation. Int. J. Pharm. 2014, 473, 591-598. [CrossRef] [PubMed]

45. Nasir, A. Nanotechnology and dermatology: Part II—risks of nanotechnology. Clin. Dermatol. 2010, 28, 581-588. [CrossRef]

46. Soriano-Ruiz, J.L.; Calpena-Capmany, A.C.; Canadas-Enrich, C.; Febrer, N.B.; Suner-Carbo, J.; Souto, E.B.; Clares-Naveros, B. Biopharmaceutical profile of a clotrimazole nanoemulsion: Evaluation on skin and mucosae as anticandidal agent. Int. J. Pharm. 2019, 554, 105-115. [CrossRef]

47. Macedo, A.S.; Quelhas, S.; Silva, A.M.; Souto, E.B. Nanoemulsions for delivery of flavonoids: Formulation and in vitro release of rutin as model drug. Pharm. Dev. Technol. 2014, 19, 677-680. [CrossRef] 
48. Souto, E.B.; Nayak, A.P.; Murthy, R.S. Lipid nanoemulsions for anti-cancer drug therapy. Pharmazie 2011, 66, 473-478.

49. Teixeira, M.C.; Severino, P.; Andreani, T.; Boonme, P.; Santini, A.; Silva, A.M.; Souto, E.B. d-alpha-tocopherol nanoemulsions: Size properties, rheological behavior, surface tension, osmolarity and cytotoxicity. Saudi Pharm. J. 2017, 25, 231-235. [CrossRef]

50. Nand, K. Proniosome Gel: Potential Carrier System in Topical/Transdermal Delivery for Drugs and Cosmetics. Cosmeceuticals Pharmainfo. Net 2010, 16, 35.

51. Özgün, S. Nanoemulsions in cosmetics. Anadolu Univ. 2013, 1, 3-11.

52. Souto, E.B.; Muller, R.H. Lipid nanoparticles: Effect on bioavailability and pharmacokinetic changes. In Drug Delivery; Handbook of Experimental Pharmacology; Springer: Berlin/Heidelberg, Germany, 2010; pp. 115-141. [CrossRef]

53. Souto, E.B.; Muller, R.H. Cosmetic features and applications of lipid nanoparticles (SLN, NLC). Int. J. Cosmet. Sci. 2008, 30, 157-165. [CrossRef]

54. Arora, N.; Agarwal, S.; Murthy, R. Latest technology advances in cosmaceuticals. Int. J. Pharm. Sci. Drug Res. 2012, 4, 168-182.

55. Patidar, A.; Thakur, D.S.; Kumar, P.; Verma, J. A review on novel lipid based nanocarriers. Int. J. Pharm. Pharm. Sci. 2010, 2, 30-35.

56. Müller, R.H.; Radtke, M.; Wissing, S.A. Solid lipid nanoparticles (SLN) and nanostructured lipid carriers (NLC) in cosmetic and dermatological preparations. Adv. Drug Deliv. Rev. 2002, 54, S131-S155. [CrossRef]

57. AlZahabi, S.; Sakr, O.S.; Ramadan, A.A. Nanostructured lipid carriers incorporating prickly pear seed oil for the encapsulation of vitamin A. J. Cosmet. Derm. 2019, 18, 1875-1884. [CrossRef]

58. Suter, F.; Schmid, D.; Wandrey, F.; Zulli, F. Heptapeptide-loaded solid lipid nanoparticles for cosmetic anti-aging applications. Eur. J. Pharm. Biopharm. 2016, 108, 304-309. [CrossRef]

59. Severino, P.; Andreani, T.; Chaud, M.V.; Benites, C.I.; Pinho, S.C.; Souto, E.B. Essential oils as active ingredients of lipid nanocarriers for chemotherapeutic use. Curr. Pharm. Biotechnol. 2015, 16, 365-370. [CrossRef]

60. Carbone, C.; Martins-Gomes, C.; Caddeo, C.; Silva, A.M.; Musumeci, T.; Pignatello, R.; Puglisi, G.; Souto, E.B. Mediterranean essential oils as precious matrix components and active ingredients of lipid nanoparticles. Int. J. Pharm. 2018, 548, 217-226. [CrossRef]

61. Souto, E.B.; Muller, R.H. SLN and NLC for topical delivery of ketoconazole. J. Microencapsul. 2005, 22, 501-510. [CrossRef]

62. Souto, E.B.; Muller, R.H. Investigation of the factors influencing the incorporation of clotrimazole in SLN and NLC prepared by hot high-pressure homogenization. J. Microencapsul. 2006, 23, 377-388. [CrossRef]

63. Souto, E.B.; Muller, R.H. The use of SLN and NLC as topical particulate carriers for imidazole antifungal agents. Pharmazie 2006, 61, 431-437. [PubMed]

64. Vieira, R.; Severino, P.; Nalone, L.A.; Souto, S.B.; Silva, A.M.; Lucarini, M.; Durazzo, A.; Santini, A.; Souto, E.B. Sucupira Oil-Loaded Nanostructured Lipid Carriers (NLC): Lipid Screening, Factorial Design, Release Profile, and Cytotoxicity. Molecules 2020, 25, 685. [CrossRef] [PubMed]

65. Zielinska, A.; Ferreira, N.R.; Durazzo, A.; Lucarini, M.; Cicero, N.; Mamouni, S.E.; Silva, A.M.; Nowak, I.; Santini, A.; Souto, E.B. Development and Optimization of Alpha-Pinene-Loaded Solid Lipid Nanoparticles (SLN) Using Experimental Factorial Design and Dispersion Analysis. Molecules 2019, 24, 2683. [CrossRef] [PubMed]

66. Zielinska, A.; Martins-Gomes, C.; Ferreira, N.R.; Silva, A.M.; Nowak, I.; Souto, E.B. Anti-inflammatory and anti-cancer activity of citral: Optimization of citral-loaded solid lipid nanoparticles (SLN) using experimental factorial design and LUMiSizer(R). Int. J. Pharm. 2018, 553, 428-440. [CrossRef] [PubMed]

67. Borchard, G. Drug Nanocrystals. In Non-Biological Complex Drugs: The Science and the Regulatory Landscape; Crommelin, D.J.A., de Vlieger, J.S.B., Eds.; Springer International Publishing: Cham, Switzerland, 2015. [CrossRef]

68. Ye, Y.; Mao, S.; He, S.; Xu, X.; Cao, X.; Wei, Z.; Gunasekaran, S. Ultrasensitive electrochemical genosensor for detection of CaMV35S gene with Fe3O4-Au@Ag nanoprobe. Talanta 2020, 206, 120205. [CrossRef] [PubMed]

69. Liu, T.; Yao, G.; Liu, X.; Yin, H. Preparation Nanocrystals of Poorly Soluble Plant Compounds Using an Ultra-Small-Scale Approach. AAPS Pharmscitech 2017, 18, 2610-2617. [CrossRef]

70. Chaudhri, N.; Soni, G.C.; Prajapati, S. Nanotechnology: An advance tool for nano-cosmetics preparation. Int. J. Pharma Res. Rev. 2015, 4, 28-40. 
71. Lai, F.; Schlich, M.; Pireddu, R.; Fadda, A.M.; Sinico, C. Nanocrystals as Effective Delivery Systems of Poorly Water-soluble Natural Molecules. Curr. Med. Chem. 2019, 26, 4657-4680. [CrossRef]

72. Liu, T.; Muller, R.H.; Moschwitzer, J.P. Production of drug nanosuspensions: Effect of drug physical properties on nanosizing efficiency. Drug Dev. Ind. Pharm. 2018, 44, 233-242. [CrossRef]

73. Nimesh, S. Dendrimers. In Gene Therapy-Potential Applications of Nanotechnology, 1st ed.; Nimesh, S., Ed.; Woodhead Publishing: Cambridge, UK, 2013; Chapter 13. [CrossRef]

74. Arif, T.; Adil, M. Nanotechnology-Dermatological Perspective. Int. J. Nanomed. Nanosurg. 2016, 2. [CrossRef]

75. Maignan, J.; Genard, S. Use of Hyperbranched Polymers and Dendrimers Comprising a Particular Group as Film-Forming Agent, Film-Forming Compositions Comprising Same and Use Particularly in Cosmetics and Pharmaceutics. U.S. Patent US6432423B1, 13 August 2002.

76. Adams, G.; Ashton, M.R.; Khoshdel, E. Cosmetic or Dermatological Topical Compositions Containing Dendritic Polyesters. European Patent EP0987017, 13 June 2001.

77. Bangham, A.D.; Horne, R. Negative staining of phospholipids and their structural modification by surface-active agents as observed in the electron microscope. J. Mol. Biol. 1964, 8, 660-668, IN2-IN10. [CrossRef]

78. Pashirova, T.N.; Zueva, I.V.; Petrov, K.A.; Lukashenko, S.S.; Nizameev, I.R.; Kulik, N.V.; Voloshina, A.D.; Almasy, L.; Kadirov, M.K.; Masson, P.; et al. Mixed cationic liposomes for brain delivery of drugs by the intranasal route: The acetylcholinesterase reactivator 2-PAM as encapsulated drug model. Colloids Surf. B Biointerfaces 2018, 171, 358-367. [CrossRef] [PubMed]

79. Teixeira, M.C.; Carbone, C.; Souto, E.B. Beyond liposomes: Recent advances on lipid based nanostructures for poorly soluble/poorly permeable drug delivery. Prog. Lipid Res. 2017, 68, 1-11. [CrossRef] [PubMed]

80. Souto, E.B. A special issue on Lipid-based delivery systems (liposomes, lipid nanoparticles, lipid matrices and medicines). J. Biomed. Nanotechnol. 2009, 5, 315-316. [CrossRef] [PubMed]

81. Pashirova, T.N.; Sapunova, A.S.; Lukashenko, S.S.; Burilova, E.A.; Lubina, A.P.; Shaihutdinova, Z.M.; Gerasimova, T.P.; Kovalenko, V.I.; Voloshina, A.D.; Souto, E.B.; et al. Synthesis, structure-activity relationship and biological evaluation of tetracationic gemini Dabco-surfactants for transdermal liposomal formulations. Int. J. Pharm. 2020, 575, 118953. [CrossRef]

82. Maherani, B.; Arab-Tehrany, E.; Mozafari, M.R.; Gaiani, C.; Linder, M. Liposomes: A review of manufacturing techniques and targeting strategies. Curr. Nanosci. 2011, 7, 436-452. [CrossRef]

83. Schmid, M.H.; Korting, H.C. Liposomes for atopic dry skin: The rationale for a promising approach. Clin. Investig. 1993, 71, 649-653. [CrossRef] [PubMed]

84. Suntres, Z.E. Liposomal Antioxidants for Protection against Oxidant-Induced Damage. J. Toxicol. 2011, 2011, 152474. [CrossRef]

85. Arif, T.; Nisa, N.; Amin, S.S.; Shoib, S.; Mushtaq, R.; Shawl, M.R. Therapeutic and diagnostic applications of nanotechnology in dermatology and cosmetics. J. Nanomed. Biother. Discov. 2015, 5, 1.

86. Ghyczy, M.; Nissen, H.; Biltz, H. The treatment of acne vulgaris by phosphatidylcholine from soybeans, with a high content of linoleic acid. J. Appl. Cosmetol. 1996, 14, 137-146.

87. Mota, A.d.C.V.; de Freitas, Z.M.F.; Ricci Júnior, E.; Dellamora-Ortiz, G.M.; Santos-Oliveira, R.; Ozzetti, R.A.; Vergnanini, A.L.; Ribeiro, V.L.; Silva, R.S.; dos Santos, E.P. In vivo and in vitro evaluation of octyl methoxycinnamate liposomes. Int. J. Nanomed. 2013, 8, 4689-4701. [CrossRef]

88. Zhao, X.; Lai, E.P.C. Titania and Zinc Oxide Nanoparticles: Coating with Polydopamine and Encapsulation within Lecithin Liposomes-Water Treatment Analysis by Gel Filtration Chromatography with Fluorescence Detection. Separations 2018, 5, 13. [CrossRef]

89. Blume, G. Flexible liposomes for topical applications in cosmetics. Sci. Appl. Skin Deliv. Syst. 2008, 269-282.

90. Ahmad, T.B.; Rudd, D.; Kotiw, M.; Liu, L.; Benkendorff, K. Correlation between Fatty Acid Profile and Anti-Inflammatory Activity in Common Australian Seafood by-Products. Mar. Drugs 2019, 17, 155. [CrossRef]

91. Kazi, K.M.; Mandal, A.S.; Biswas, N.; Guha, A.; Chatterjee, S.; Behera, M.; Kuotsu, K. Niosome: A future of targeted drug delivery systems. J. Adv. Pharm. Technol. Res. 2010, 1, 374.

92. Chandu, V.P.; Arunachalam, A.; Jeganath, S.; Yamini, K.; Tharangini, K.; Chaitanya, G. Niosomes: A novel drug delivery system. Int. J. Novel Trends Pharm. Sci. 2012, 2, 25-31.

93. Kumar, G.P.; Rajeshwarrao, P. Nonionic surfactant vesicular systems for effective drug delivery-An overview. Acta Pharm. Sin. B 2011, 1, 208-219. [CrossRef] 
94. Gandhi, M.; Sanket, P.; Mahendra, S. Niosomes: Novel drug delivery system. Int. J. Pure Appl. Biosci. 2014, 2, 267-274.

95. Verma, S.; Singh, S.; Syan, N.; Mathur, P.; Valecha, V. Nanoparticle vesicular systems: A versatile tool for drug delivery. J. Chem. Pharm. Res. 2010, 2, 496-509.

96. Varun, T.; Sonia, A.; Bharat, P.; Patil, V. Niosomes and liposomes-vesicular approach towards transdermal drug delivery. Int. J. Pharm. Chem. Sci. 2012, 1, 632-644.

97. Nasir, A.; Harikumar, S.; Amanpreet, K. Niosomes: An excellent tool for drug delivery. Int. J. Res. Pharm. Chem. 2012, 2, 479-487.

98. Sánchez-López, E.; Gomes, D.; Esteruelas, G.; Bonilla, L.; Lopez-Machado, A.L.; Galindo, R.; Cano, A.; Espina, M.; Ettcheto, M.; Camins, A.; et al. Metal-Based Nanoparticles as Antimicrobial Agents: An Overview. Nanomaterials 2020, 10, 292. [CrossRef] [PubMed]

99. Kokura, S.; Handa, O.; Takagi, T.; Ishikawa, T.; Naito, Y.; Yoshikawa, T. Silver nanoparticles as a safe preservative for use in cosmetics. Nanomedicine 2010, 6, 570-574. [CrossRef] [PubMed]

100. Pulit-Prociak, J.; Grabowska, A.; Chwastowski, J.; Majka, T.M.; Banach, M. Safety of the application of nanosilver and nanogold in topical cosmetic preparations. Colloids Surf. B Biointerfaces 2019, 183, 110416. [CrossRef]

101. Kodoth, A.K.; Ghate, V.M.; Lewis, S.A.; Prakash, B.; Badalamoole, V. Pectin-based silver nanocomposite film for transdermal delivery of Donepezil. Int. J. Biol. Macromol. 2019, 134, 269-279. [CrossRef] [PubMed]

102. Alaqad, K.; Saleh, T.A. Gold and silver nanoparticles: Synthesis methods, characterization routes and applications towards drugs. J. Environ. Anal. Toxicol. 2016, 6, 525-2161. [CrossRef]

103. Thakor, A.; Jokerst, J.; Zavaleta, C.; Massoud, T.; Gambhir, S. Gold nanoparticles: A revival in precious metal administration to patients. Nano Lett. 2011, 11, 4029-4036. [CrossRef]

104. Guterres, S.S.; Alves, M.P.; Pohlmann, A.R. Polymeric nanoparticles, nanospheres and nanocapsules, for cutaneous applications. Drug Target Insights 2007, 2, 147-157. [CrossRef]

105. Tahir, M.A.; Ali, M.E.; Lamprecht, A. Nanoparticle formulations as recrystallization inhibitors in transdermal patches. Int. J. Pharm. 2020, 575, 118886. [CrossRef]

106. Abrego, G.; Alvarado, H.; Souto, E.B.; Guevara, B.; Bellowa, L.H.; Garduno, M.L.; Garcia, M.L.; Calpena, A.C. Biopharmaceutical profile of hydrogels containing pranoprofen-loaded PLGA nanoparticles for skin administration: In vitro, ex vivo and in vivo characterization. Int. J. Pharm. 2016, 501, 350-361. [CrossRef]

107. Gilbert, E.; Roussel, L.; Serre, C.; Sandouk, R.; Salmon, D.; Kirilov, P.; Haftek, M.; Falson, F.; Pirot, F. Percutaneous absorption of benzophenone-3 loaded lipid nanoparticles and polymeric nanocapsules: A comparative study. Int. J. Pharm. 2016, 504, 48-58. [CrossRef] [PubMed]

108. Hu, F.; Liu, W.; Yan, L.; Kong, F.; Wei, K. Optimization and characterization of poly(lactic-co-glycolic acid) nanoparticles loaded with astaxanthin and evaluation of anti-photodamage effect in vitro. R. Soc. Open Sci. 2019, 6, 191184. [CrossRef] [PubMed]

109. Ito, F.; Takahashi, T.; Kanamura, K.; Kawakami, H. Possibility for the development of cosmetics with PLGA nanospheres. Drug Dev. Ind. Pharm. 2013, 39, 752-761. [CrossRef] [PubMed]

110. Liu, J. Pharmacology of oleanolic acid and ursolic acid. J. Ethnopharmacol. 1995, 49, 57-68. [CrossRef]

111. Silva, A.M.; Alvarado, H.L.; Abrego, G.; Martins-Gomes, C.; Garduno-Ramirez, M.L.; Garcia, M.L.; Calpena, A.C.; Souto, E.B. In Vitro Cytotoxicity of Oleanolic/Ursolic Acids-Loaded in PLGA Nanoparticles in Different Cell Lines. Pharmaceutics 2019, 11, 362. [CrossRef]

112. Matos, B.N.; Reis, T.A.; Gratieri, T.; Gelfuso, G.M. Chitosan nanoparticles for targeting and sustaining minoxidil sulphate delivery to hair follicles. Int. J. Biol. Macromol. 2015, 75, 225-229. [CrossRef]

113. Archana, D.; Singh, B.K.; Dutta, J.; Dutta, P.K. In vivo evaluation of chitosan-PVP-titanium dioxide nanocomposite as wound dressing material. Carbohydr. Polym. 2013, 95, 530-539. [CrossRef]

114. Ibrahim, K.S. Carbon nanotubes? properties and applications: A review. Carbon Lett. 2013, 14, $131-144$.

115. Hirlekar, R.; Yamagar, M.; Garse, H.; Vij, M.; Kadam, V. Carbon nanotubes and its applications: A review. Asian J. Pharm. Clin. Res. 2009, 2, 17-27.

116. Zhang, M.; Li, J. Carbon nanotube in different shapes. Mater. Today 2009, 12, 12-18. [CrossRef]

117. Kim, S.-H.; Shum, H.C.; Kim, J.W.; Cho, J.-C.; Weitz, D.A. Multiple polymersomes for programmed release of multiple components. J. Am. Chem. Soc. 2011, 133, 15165-15171. [CrossRef] [PubMed]

118. Bermudez, H.; Brannan, A.K.; Hammer, D.A.; Bates, F.S.; Discher, D.E. Molecular weight dependence of polymersome membrane structure, elasticity, and stability. Macromolecules 2002, 35, 8203-8208. [CrossRef] 
119. Zhang, X.-Y.; Zhang, P.-Y. Polymersomes in nanomedicine-A review. Curr. Nanosci. 2017, 13, $124-129$. [CrossRef]

120. Bhosale, R.R.; Osmani, R.A.; Harkare, B.R.; Ghodake, P.P. Cubosomes: The inimitable nanoparticulate drug carriers. Sch. Acad. J. Pharm. 2013, 2, 481-486.

121. Thadanki, M.; Kumari, P.S.; Prabha, K.S. Overview of cubosomes: A nano particle. Int. J. Res. Pharm. Chem. 2011, 1, 535-541.

122. Smijs, T.G.; Pavel, S. Titanium dioxide and zinc oxide nanoparticles in sunscreens: Focus on their safety and effectiveness. Nanotechnol. Sci. Appl. 2011, 4, 95. [CrossRef]

123. Hu, Z.; Liao, M.; Chen, Y.; Cai, Y.; Meng, L.; Liu, Y.; Lv, N.; Liu, Z.; Yuan, W. A novel preparation method for silicone oil nanoemulsions and its application for coating hair with silicone. Int. J. Nanomed. 2012, 7, 5719.

124. Ünlü, E.; Erdem, C. Deri yaşlanmasında korunma ve tedavi yöntemleri. Dermatoz 2010, 1, $23-31$.

125. Otlatıcı, G.; Yeğen, G.; Güngör, S.; Aksu, B. Overview on nanotechnology based cosmeceuticals to prevent skin aging. Istanb. J. Pharm. 2018, 48, 55-62. [CrossRef]

126. Farage, M.A.; Miller, K.W.; Elsner, P.; Maibach, H.I. Structural characteristics of the aging skin: A review. Cutan. Ocul. Toxicol. 2007, 26, 343-357. [CrossRef]

127. Türsen, Ü. Deri Yaşlanmasının Topikal Ajanlarla Önlenmesi. Dermatose 2006, 4, 267-283.

128. de Araújo, R.; Lôbo, M.; Trindade, K.; Silva, D.F.; Pereira, N. Fibroblast Growth Factors: A Controlling Mechanism of Skin Aging. Skin Pharmacol. Physiol. 2019, 32, 275-282. [CrossRef] [PubMed]

129. Campos, J.R.; Severino, P.; Ferreira, C.S.; Zielinska, A.; Santini, A.; Souto, S.B.; Souto, E.B. Linseed Essential Oil-Source of Lipids as Active Ingredients for Pharmaceuticals and Nutraceuticals. Curr. Med. Chem 2019, 26, 4537-4558. [CrossRef] [PubMed]

130. Pereira, I.; Zielinska, A.; Ferreira, N.R.; Silva, A.M.; Souto, E.B. Optimization of linalool-loaded solid lipid nanoparticles using experimental factorial design and long-term stability studies with a new centrifugal sedimentation method. Int. J. Pharm. 2018, 549, 261-270. [CrossRef]

131. Durazzo, A.; Lucarini, M.; Novellino, E.; Souto, E.B.; Daliu, P.; Santini, A. Abelmoschus esculentus (L.): Bioactive Components' Beneficial Properties-Focused on Antidiabetic Role-For Sustainable Health Applications. Molecules 2018, 24, 38. [CrossRef]

132. Lucarini, M.; Durazzo, A.; Kiefer, J.; Santini, A.; Lombardi-Boccia, G.; Souto, E.B.; Romani, A.; Lampe, A.; Ferrari Nicoli, S.; Gabrielli, P.; et al. Grape Seeds: Chromatographic Profile of Fatty Acids and Phenolic Compounds and Qualitative Analysis by FTIR-ATR Spectroscopy. Foods 2019, 9, 10. [CrossRef]

133. Taghouti, M.; Martins-Gomes, C.; Schäfer, J.; Félix, L.M.; Santos, J.A.; Bunzel, M.; Nunes, F.M.; Silva, A.M. Thymus pulegioides L. as a rich source of antioxidant, anti-proliferative and neuroprotective phenolic compounds. Food Funct. 2018, 9, 3617-3629. [CrossRef]

134. Martins-Gomes, C.; Taghouti, M.; Schäfer, J.; Bunzel, M.; Silva, A.M.; Nunes, F.M. Chemical characterization and bioactive properties of decoctions and hydroethanolic extracts of Thymus carnosus Boiss. J. Funct. Foods 2018, 43, 154-164. [CrossRef]

135. Allemann, I.B.; Baumann, L. Botanicals in skin care products. Int. J. Dermatol. 2009, 48, 923-934. [CrossRef]

136. Martins-Gomes, C.; Souto, E.B.; Cosme, F.; Nunes, F.M.; Silva, A.M. Thymus carnosus extracts induce anti-proliferative activity in Caco-2 cells through mechanisms that involve cell cycle arrest and apoptosis. J. Funct. Foods 2019, 54, 128-135. [CrossRef]

137. Sorg, O.; Kuenzli, S.; Kaya, G.; Saurat, J.H. Proposed mechanisms of action for retinoid derivatives in the treatment of skin aging. J. Cosmet. Dermatol. 2005, 4, 237-244. [CrossRef] [PubMed]

138. Sharma, B.; Sharma, A. Future prospect of nanotechnology in development of anti-ageing formulations. Int. J. Pharm. Pharm. Sci. 2012, 4, 57-66.

139. Lazarus, M.C.; Baumann, L.S. The use of cosmeceutical moisturizers. Dermatol. Ther. 2001, 14, $200-207$. [CrossRef]

140. Graf, J. Anti-aging skin care ingredient technologies. In Cosmetic Dermatology; Springer: Berlin, Germany, 2005; pp. 17-28.

141. Gondikas, A.P.; Kammer, F.v.d.; Reed, R.B.; Wagner, S.; Ranville, J.F.; Hofmann, T. Release of TiO2 nanoparticles from sunscreens into surface waters: A one-year survey at the old Danube recreational Lake. Environ. Sci. Technol. 2014, 48, 5415-5422. [CrossRef] [PubMed]

142. Gupta, A.; Eral, H.B.; Hatton, T.A.; Doyle, P.S. Nanoemulsions: Formation, properties and applications. Soft Matter 2016, 12, 2826-2841. [CrossRef] [PubMed] 
143. Danti, S.; Trombi, L.; Fusco, A.; Azimi, B.; Lazzeri, A.; Morganti, P.; Coltelli, M.B.; Donnarumma, G. Chitin Nanofibrils and Nanolignin as Functional Agents in Skin Regeneration. Int. J. Mol. Sci. 2019, $20,2669$. [CrossRef]

144. Morganti, P.; Morganti, G.; Colao, C. Biofunctional Textiles for Aging Skin. Biomedicines 2019, 7, 51. [CrossRef]

145. Habibi, Y. Key advances in the chemical modification of nanocelluloses. Chem. Soc. Rev. 2014, 43, 1519-1542. [CrossRef]

146. Ni, Y.; Khan, A.; Wang, B. Chitosan-Nanocellulose Composites for Regenerative Medicine Applications. Curr. Med. Chem. 2020, in press. [CrossRef]

147. Schutz, C.; Sort, J.; Bacsik, Z.; Oliynyk, V.; Pellicer, E.; Fall, A.; Wagberg, L.; Berglund, L.; Bergstrom, L.; Salazar-Alvarez, G. Hard and transparent films formed by nanocellulose-TiO2 nanoparticle hybrids. PLoS ONE 2012, 7, e45828. [CrossRef]

(C) 2020 by the authors. Licensee MDPI, Basel, Switzerland. This article is an open access article distributed under the terms and conditions of the Creative Commons Attribution (CC BY) license (http://creativecommons.org/licenses/by/4.0/). 